\title{
Defining the chromatin signature of inducible genes in $\mathbf{T}$ cells Pek S Lim ${ }^{\not *}$, Kristine Hardy ${ }^{\star *}$, Karen L Bunting ${ }^{\dagger}$, Lina $\mathrm{Ma}^{*}$, Kaiman Peng Xinxin Chen and Mary F Shannon*
}

\begin{abstract}
Addresses: *Genome Biology Program and ACRF Biomolecular Resource Facility, John Curtin School of Medical Research, The Australian National University, Garran Road, Acton, ACT 0200, Australia. ${ }^{\dagger}$ Current address: Department of Medicine/Hematology-Oncology, Weill Cornell Medical College, 68th St, New York, NY 10065, USA. ${ }^{\ddagger}$ Current address: Departments of Physiology and Pathology, National Laboratory of Medical Molecular Biology, Institute of Basic Medical Sciences and School of Basic Medicine, Chinese Academy of Medical Sciences and Peking Union Medical College, 1 Shuaifuyuan, Beijing 100730, PR China.
\end{abstract}

$\ltimes$ These authors contributed equally to this work.

Correspondence: Mary F Shannon. Email: frances.shannon@anu.edu.au

Published: 6 October 2009

Genome Biology 2009, 10:RI07 (doi:10.1 186/gb-2009-10-10-r107)

The electronic version of this article is the complete one and can be found online at http://genomebiology.com/2009//0//0/R/07
Received: 30 April 2009

Revised: 27 July 2009

Accepted: 6 October 2009

(c) 2009 Lim et al.; licensee BioMed Central Ltd.

This is an open access article distributed under the terms of the Creative Commons Attribution License (http://creativecommons.org/licenses/by/2.0), which permits unrestricted use, distribution, and reproduction in any medium, provided the original work is properly cited.

\begin{abstract}
Background: Specific chromatin characteristics, especially the modification status of the core histone proteins, are associated with active and inactive genes. There is growing evidence that genes that respond to environmental or developmental signals may possess distinct chromatin marks. Using a $T$ cell model and both genome-wide and gene-focused approaches, we examined the chromatin characteristics of genes that respond to $T$ cell activation.

Results: To facilitate comparison of genes with similar basal expression levels, we used expression-profiling data to bin genes according to their basal expression levels. We found that inducible genes in the lower basal expression bins, especially rapidly induced primary response genes, were more likely than their non-responsive counterparts to display the histone modifications of active genes, have RNA polymerase II (Pol II) at their promoters and show evidence of ongoing basal elongation. There was little or no evidence for the presence of active chromatin marks in the absence of promoter Pol II on these inducible genes. In addition, we identified a subgroup of genes with active promoter chromatin marks and promoter Pol II but no evidence of elongation. Following $T$ cell activation, we find little evidence for a major shift in the active chromatin signature around inducible gene promoters but many genes recruit more Pol II and show increased evidence of elongation.
\end{abstract}

Conclusions: These results suggest that the majority of inducible genes are primed for activation by having an active chromatin signature and promoter Pol II with or without ongoing elongation. 


\section{Background}

The timed and coordinated regulation of gene expression is important at every developmental stage of a multicellular organism as well as in the response of the organism to environmental changes. One of the central regulators of eukaryotic gene transcription is the organization of the genome into chromatin. Histone proteins are key components of chromatin, forming the basic nucleosome packaging structure. Over the past decade, the post-translational modification of histone proteins has been shown to have a complex role in controlling gene expression (reviewed in $[1,2]$ ). In general, actively transcribed genes are associated with lysine acetylation on histones $\mathrm{H}_{3}$ and $\mathrm{H}_{4}$ and with methylation of histone $\mathrm{H}_{3}$ on lysine 4 ( $\left.\mathrm{H}_{3} \mathrm{~K} 4 \mathrm{me}\right)$. On the other hand, methylation of lysine $9\left(\mathrm{H}_{3} \mathrm{~K} 9 \mathrm{me}\right)$ or lysine $27\left(\mathrm{H}_{3} \mathrm{~K} 27 \mathrm{me}\right)$ on $\mathrm{H}_{3}$ is associated with repression. Many protein complexes responsible for adding or removing these modifications have been isolated and shown to play important roles in controlling gene expression (reviewed in [1]).

In terms of chromatin packaging, these histone modifications are considered to be important in inter-nucleosome interactions and higher order chromatin packaging [3]. In relation to gene transcription, they can form important binding surfaces on nucleosomes for chromatin binding proteins that play key roles in gene transcription (reviewed in [1]). These observations have led to the idea of a 'histone code' that marks chromatin domains in the eukaryotic nucleus and either plays a role in controlling gene transcription or is a result of the transcriptional activity of that locus.

Although the 'histone code' that marks active and inactive genes has now been characterized in some detail, there is less information in regard to the chromatin status of inducible genes prior to activation. Of particular interest in this regard are recent genome-wide studies of histone marks in mouse pluripotent embryonic stem cells that have defined a class of developmentally regulated genes as 'bivalent' - genes marked with both active (histone $\mathrm{H}_{3}$ lysine 4 trimethyl ( $\left.\mathrm{H}_{3} \mathrm{~K}_{4} \mathrm{me}_{3}\right)$ ) and repressive (histone $\mathrm{H}_{3}$ lysine 27 trimethyl (H3K27me3)) histone modifications [4-6] Furthermore, many of these bivalent genes are found to have RNA polymerase II (Pol II) located at their promoters in what is proposed to be a poised state [7]. The existence of a bivalent state has also been shown on some genes in other types of stem cells and in more differentiated cells, implying that this chromatin state may be involved in controlling genes that respond to developmental or environmental signals in all cell types [8-11]. Sequential chromatin immunoprecipitation (ChIP) has been used in a couple of cases to clearly show the bivalent nature of specific genes $[5,8]$. Following differentiation, it has been shown that these genes often resolve into a monovalent state for expression or repression $[5,9,10]$. Whether genes that respond rapidly to cellular activation signals also display bivalent chromatin marks remains to be examined.
It has long been known that certain inducible genes, such as the heat shock genes [12-14] and some oncogenes $[15,16]$, have Pol II paused or stalled close to the start of gene transcription and that an increased elongation rate plays a role in their response to signaling. Not only inducible genes but many other genes also show evidence of pausing even with detectable transcription, implying that this constitutes a common mechanism to control the transcription rate [15]. More recently, genome-wide studies in mouse and human embryonic stem cells and differentiated human cells have identified large numbers of genes where Pol II is located at the promoter in the absence of ongoing transcription and these genes are often referred to as poised $[5,17,18]$. In yeast, Pol II was constitutively bound to hundreds of promoter regions that are activated immediately following exit from stationary phase [18]. Recent genome-wide studies in Drosophila have also defined groups of genes with promoter-enriched Pol II, a feature that is postulated to facilitate rapid induction of transcription of these genes [19-21]. These studies have led to the definition of three classes of genes based on Pol II location $[17,22]$. Genes in the first class lack Pol II and are considered as inactive. The second class includes active genes where Pol II can be detected at both the promoter and in the body of the gene, but it should be noted that, in general, the level of Pol II in the body of the gene is lower than at the promoter or the 3 ' end. The third class consists of those genes where Pol II is detected at the promoter but not in the body of the gene and are considered potentially active. Genes in this third class are generally referred to as poised genes and are enriched for developmental control genes and genes that respond to developmental or environmental signals [20,21]. Recent evidence in Drosophila suggests that genes with promoter-proximal enrichment of Pol II can span a wide range of expression levels, supporting the idea that promoter proximal pausing is a common mechanism used to control transcription rate [20,23]. These data in turn suggest that the regulation of elongation may play an important role in the response of genes to environmental signals.

The mature cells of the immune system represent an exquisitely poised system for rapid response to pathogens and thus can be used to investigate the chromatin characteristics of genes that respond rapidly to extracellular signals. Recent genome-wide studies in human $\mathrm{T}$ cells have extensively characterized a large number of histone modifications using ChIP combined with massively parallel sequencing (ChIP-Seq) and identified modification patterns associated with enhancers, promoters, other genomic control regions as well as conserved domains [24-28]. These studies have also defined histone modification patterns associated with active and inactive genes, but the patterns associated with inducible genes were not examined in any detail [24-28]. Earlier studies have shown that many new regions of acetylation appear in response to $\mathrm{T}$ cell activation, suggesting that inducible genes may change their chromatin signature in response to activation $[26,29]$. 
Using three approaches - ChIP combined with microarray technology (ChIP-on-chip), mining of ChIP-Seq data and ChIP with quantitative PCR (ChIP-qPCR) - for individual genes, we sought to define the chromatin signature of inducible genes in T cells. To facilitate comparison of genes with similar basal expression levels, genes were binned according to their basal expression levels determined from expression profiling studies. Our results show that inducible genes in the lower basal expression bins, especially rapidly induced primary response genes, were more likely to display the chromatin characteristics of active genes than their non-responsive counterparts.

\section{Results \\ An active histone acetylation signature at inducible gene promoters}

To ask whether $\mathrm{T}$ cell inducible genes have a defined chromatin signature, genome-wide approaches were used to both identify inducible genes and to examine the chromatin characteristics of these genes. First, expression profiling was performed on non-stimulated or phorbol 12-myristate 13-acetate and ionomycin (P/I)-treated ( $4 \mathrm{~h}$ ) EL-4 T cells with or without cycloheximide ( $\mathrm{CHX})$ treatment, and inducible genes were identified (false discovery rate $(\mathrm{FDR})<0.1$ ) and grouped into primary (539 genes; those genes whose expression was not inhibited by CHX and thus do not need new protein synthesis for expression) and secondary (1,238 genes; those genes whose expression was inhibited by CHX and thus require new protein synthesis for expression) gene groups dependent on their response to $\mathrm{CHX}$ treatment. Both of the gene groups displayed a wide spread of basal mRNA expression levels but, on average, the primary and secondary groups displayed higher basal expression levels compared with the unchanged group or all genes (Additional data file 1a), implying that many inducible genes are already producing detectable transcripts. Therefore, to ensure comparison of genes with similar basal expression levels, the primary, secondary and unchanged groups were binned according to their basal mRNA expression levels (Table 1 ). The numbers of primary

\section{Table I}

The number of expression array probes in the basal expression bins for the gene groups

Basal expression $\left(\log _{2}\right) *$

4 to $5 \quad 5$ to $6 \quad 6$ to $7 \quad 7$ to $8 \quad 8$ to $9 \quad 9$ to 10

\begin{tabular}{lcccccc}
\hline Primary & 15 & 51 & 94 & 147 & 128 & 58 \\
Secondary & 94 & 187 & 205 & 232 & 228 & 158 \\
Unchanged & 3570 & 2972 & 820 & 394 & 261 & 193 \\
\hline
\end{tabular}

*Genes were placed into bins according to their basal expression (robust multichip average $\log _{2}$ ) values. ${ }^{\prime}$ Genes were classified according to the kinetics of their response to $\mathrm{P} / \mathrm{l}$ stimulation and their requirement for new protein synthesis. response genes in the lower expression bins $\left(\log _{2} 3\right.$ to 4 and 4 to 5) were small and thus could not be treated in a sound statistical manner (Additional data file 7; noted as NA or not applicable).

ChIP-on-chip experiments on unstimulated EL-4 cells were performed using $\mathrm{H}_{3} \mathrm{~K} 9 \mathrm{ac}$ and $\mathrm{H}_{3}$ antibodies and Affymetrix mouse promoter arrays (1.0R) and the data were analyzed using the model-based analysis of tiling array (MAT) algorithm [30]. The promoter region of a gene was defined as -1.2 $\mathrm{kb}$ to $+0.6 \mathrm{~kb}$ from the transcriptional start site (TSS) and the highest score of any overlapping $\mathrm{H}_{3} \mathrm{~K} 9 \mathrm{ac}$ or $\mathrm{H}_{3}$ region detected by MAT was used as the score for that gene. As expected from previous studies showing an association between gene expression and $\mathrm{H}_{3} \mathrm{~K} 9 \mathrm{ac}[28,31]$, all gene groups showed an increase in the median $\mathrm{H}_{3} \mathrm{~K} 9 \mathrm{ac}$ MAT region score as their basal mRNA expression levels increased (Figure 1a) but control immunoprecipitations did not show this pattern (Additional data file $1 \mathrm{~b}$ ). In general, both the primary and secondary gene groups displayed significantly higher median levels of $\mathrm{H}_{3} \mathrm{~K}$ 9ac compared to the unchanged gene group (Figure 1a) with the statistical significance of the differences decreasing with increasing basal expression (Additional data file 7; compare $\log _{2} 5$ to 6 with $\log _{2} 9$ to 10 for primary or secondary versus unchanged). In addition, the primary response genes were significantly more acetylated than the secondary response genes in some but not all basal expression bins (Figure 1a; Additional data file 7). Because the underlying histone density can vary across the genome, especially at promoter regions, the $\mathrm{H}_{3} \mathrm{~K} 9$ acetylation values were also calculated relative to the total histone $\mathrm{H}_{3}$ scores with very similar results (Figure 1b; Additional data file 7).

Within each binned gene group there was a considerable spread of acetylation values, so we next asked if the percentage of genes above a specific acetylation score threshold was higher for the inducible gene groups. If a MAT score of 35.2 (FDR of 0.05) was set as a threshold and genes above this score designated as acetylated, then a significantly greater percentage of primary and secondary response genes were acetylated compared with the unchanged genes in the $\log _{2} 5$ to 6, 6 to 7 and 7 to 8 expression bins (Figure 1c; Additional data file 7). These data suggest that inducible genes with lower basal expression have relatively high levels of acetylation in the basal state compared with non-responsive genes and may be primed for activation.

We verified these results using ChIP-qPCR for a number of genes from the basal expression $\log _{2} 5$ to 6 bin (Figure $1 \mathrm{~d}$ ). The PCR data agreed with the predictions from the array studies, with the primary genes having the highest ratio of $\mathrm{H}_{3} \mathrm{~K}$ ac: $\mathrm{H}_{3}$, followed by the secondary response genes and then the unchanged genes (Figure 1d; Additional data file 2). We also selected a group of previously well characterized inducible genes and examined the $\mathrm{H}_{3} \mathrm{~K} 9 \mathrm{ac}$ status of their promoters in non-stimulated cells. The induction levels, 


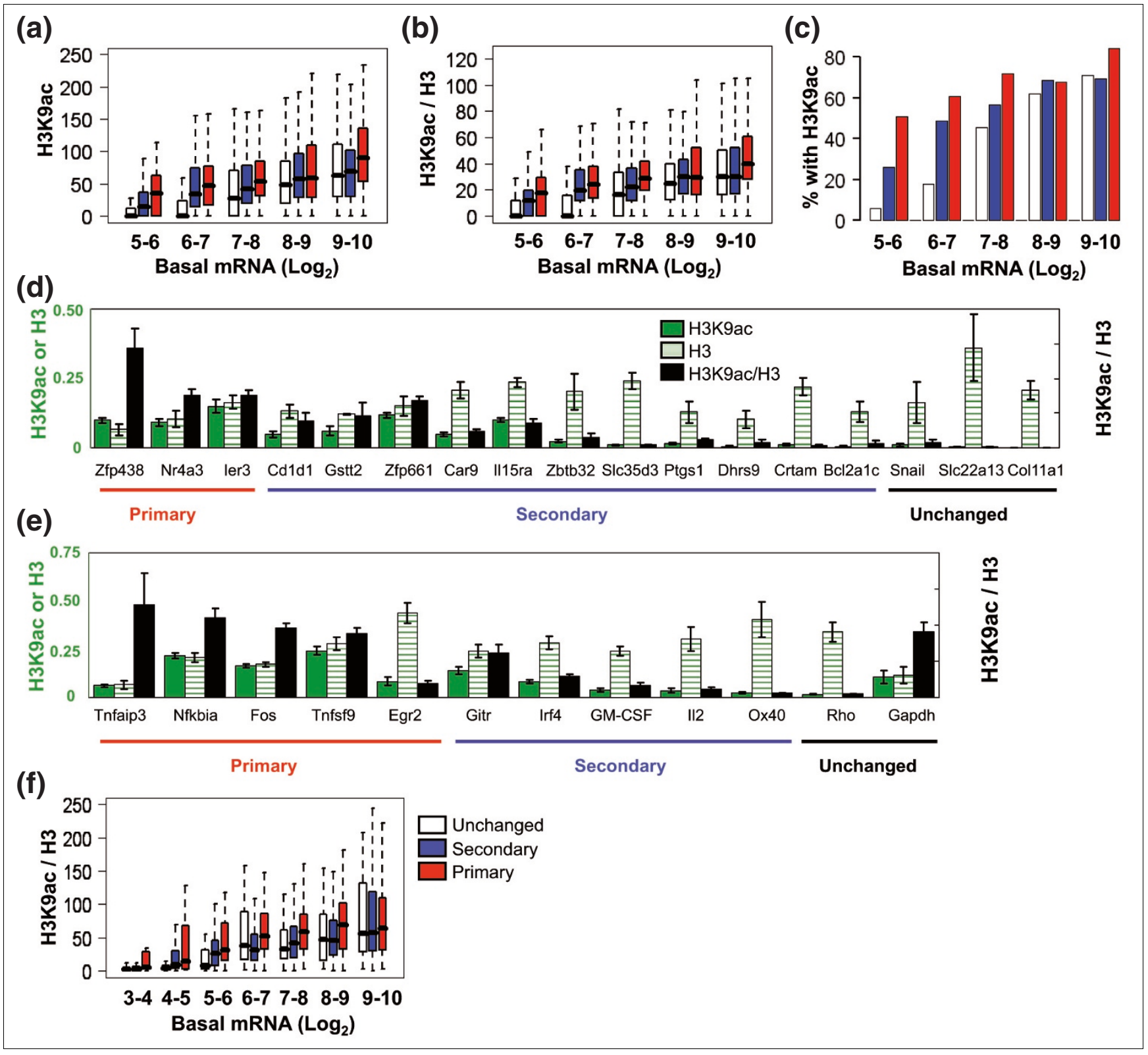

Figure I

Inducible genes have higher levels of $\mathrm{H} 3 \mathrm{~K} 9 \mathrm{ac}$ at their promoters. The $\mathrm{H} 3 \mathrm{~K} 9 \mathrm{ac}$ levels determined from ChIP-on-chip experiments are plotted for genes grouped by their kinetics of expression (red, primary response genes; blue, secondary response genes; white, unchanged genes) and their basal expression levels (Log 2 robust multichip average values from expression profiling). $(\mathbf{a}, \mathbf{b})$ Levels of $\mathrm{H} 3 \mathrm{~K} 9 \mathrm{ac}$ were compared to either total genomic input DNA (a) or total $\mathrm{H} 3$ levels determined by ChIP-on-chip (b). (c) The proportion of promoters with a H3K9ac MAT score $>35.2$ (FDR $<5 \%$ ) was plotted for each of the gene groups. Three biological replicates were performed for each ChIP-on-chip and the data combined (a-c). (d, e) Real-time PCR was used to verify the results of microarrays (d) for a selected group of genes and to examine the H3K9ac levels for a set of well characterized inducible genes at the promoter region (e). In (d) the genes are plotted from the left to right in order of decreasing predicted H3K9ac score from the ChIP-on-chip data (with H3 levels as background control). The H3K9ac/total input (green bars), the $\mathrm{H} 3$ /total input (hatched green bars) and the $\mathrm{H} 3 \mathrm{~K} 9 \mathrm{ac} / \mathrm{H} 3 \mathrm{ratios}$ (black bars) are shown (d, e). The averages of three independent experiments are plotted; $n=3$; error bars $=$ standard error of the mean. (f) Data from ChIP-Seq experiments on human CD4+ lymphocytes [28] were analyzed to determine the number of $\mathrm{H} 3 \mathrm{~K} 9 \mathrm{ac}$ sequence tags that overlapped with the promoter region $(-\mathrm{I} \mathrm{kb}$ to $+\mathrm{I}$ $\mathrm{kb})$ of each gene and the data are plotted for the different gene groups. The basal expression levels of the genes are from a matching human CD4+ lymphocyte microarray analysis [GEO:GSEI0437]. The bar marks the median score, the edges of the boxes the second and third interquartile ranges and the whiskers the first and fourth interquartile ranges $(a, b, f)$. 
response to $\mathrm{CHX}$ and basal expression levels for this gene group are shown in Additional data file 3. Four (Fos, Nfkbia, Tnfaip 3 and Tnfsf9) out of the five primary response genes displayed relatively high levels of acetylation whereas those of the secondary response group were generally lower (Figure 1e; Additional data file 2). Several control genes, the active Gapdh ( $\left.\log _{2} 13.9\right)$ and the inactive Rho ( $\left.\log _{2} 4.4\right)$, Snail, Slc22a13 and Col11a1 displayed the expected pattern for active and repressed genes, respectively (Figure 1e; Additional data file 2).

We next mined a genome-wide ChIP-Seq data set from human primary CD4+ lymphocytes [28] to find the number of $\mathrm{H}_{3} \mathrm{~K}$ 9ac tags that overlapped with the promoter regions ($1 \mathrm{~kb}$ to $+1 \mathrm{~kb}$ of the annotated TSSs) of the human orthologs of the mouse genes. The basal expression level bins were adjusted using expression profiling data available for human CD4+ lymphocytes [27] from the same investigators (Table 2). The stimulation used in the aforementioned paper was longer than the $4 \mathrm{~h}$ stimulation used in this study, so we used a data set ([GEO:GSE3720] [32]) from human $\gamma \delta \mathrm{T}$ lymphocytes stimulated for $4 \mathrm{~h}$ with $\mathrm{P} / \mathrm{I}$ to establish if the inducible genes in EL-4 T cells were also induced in human primary lymphocytes. For the primary and secondary response genes with basal expression less than $\log _{2} 6,52 \%$ and $39 \%$ of the genes, respectively, were induced compared to $25 \%$ for the unchanged group $(P<0.002)$. The profile of $\mathrm{H}_{3} \mathrm{~K} 9 \mathrm{ac}$ was very similar to that derived from the mouse ChIP-on-chip studies, with significantly higher median levels of acetylation for the primary response genes compared with the unchanged genes in the $\log _{2} 3$ to 4,4 to 5 and 5 to 6 expression bins (Figure 1f; Additional data file 7). Secondary response genes also showed some evidence of increased acetylation compared with unchanged genes in the lower basal expression bins and in some bins there were significant differences between primary and secondary genes (Figure 1f; Additional data file 7). The human data set contains information about a number of other acetylation marks and we found that the majority of the acetylation marks showed a similar pattern to $\mathrm{H}_{3} \mathrm{~K} 9 \mathrm{ac}$, with H2AK9ac, H2BK2Oac, $\mathrm{H}_{3} \mathrm{~K}_{3} 6 \mathrm{ac}$ and $\mathrm{H}_{4} \mathrm{~K}_{16} 6 \mathrm{ac}$ showing the most significant differences between the inducible and unchanged gene groups (Additional data file 4a-d). Once again, the primary response gene groups generally showed a stronger trend than the secondary response gene groups (Additional data file 4a-d).

Thus, all three approaches show that inducible genes, especially primary response genes with lower basal expression, are more likely than their non-responsive counterparts to have a histone acetylation profile that resembles active genes.

\section{Promoter GC content does not contribute to differences in acetylation levels between inducible and non-inducible genes}

Previous studies have shown that promoters without $\mathrm{CpG}$ islands are less likely to have acetylated histones than those with CpG islands [31]. We therefore divided the gene groups into those with and without $\mathrm{CpG}$ islands (Figure 2a) and asked if the presence of a $\mathrm{CpG}$ island correlated with the $\mathrm{H}_{3} \mathrm{~K}$ 9ac pattern. As expected, for the genes with $\mathrm{CpG}$ islands, acetylation levels were generally higher and a higher percentage of the genes were acetylated than those without $\mathrm{CpG}$ islands across all of the gene groups (Figure 2b-e). However, in both $\mathrm{CpG}$ and non-CpG island promoter groups, the inducible gene groups had significantly higher median acetylation scores than the unchanged genes in the lower basal expression bins (Figure 2b, c; Additional data file 7) and a significantly higher percentage of them was acetylated (Figure 2d, e; Additional data file 7). These data show that while GC content influences the level of acetylation across the entire gene set, the difference between inducible and non-inducible genes was not directly related to GC content.

\section{Inducible genes are more likely to display active histone methylation marks}

Active genes have been shown to display a high level of $\mathrm{H}_{3} \mathrm{~K}_{4}$ trimethylation $\left(\mathrm{H}_{3} \mathrm{~K}_{4} \mathrm{me}_{3}\right)$ whereas inactive genes have low levels of $\mathrm{H}_{4} \mathrm{~K}_{4} \mathrm{me} 3$ but high levels of $\mathrm{H}_{3} \mathrm{~K} 27 \mathrm{me} 3$ [25,33]. In genome-wide studies in embryonic stem cells, genes with CpG islands that are destined to be activated later in development display both active $\left(\mathrm{H}_{3} \mathrm{~K}_{4} \mathrm{me} 3\right)$ and inactive ( $\mathrm{H}_{3} \mathrm{~K} 27 \mathrm{me}$ ) histone marks and have been described as 'bivalent' $[5,6]$. Therefore, we next examined the patterns of the permissive $\mathrm{H}_{3} \mathrm{~K}_{4} \mathrm{me} 3$ and the repressive $\mathrm{H}_{3} \mathrm{~K} 27 \mathrm{me} 3$ marks from the ChIP-Seq data set in human CD4+ T cells. As expected, these two methylation marks showed a reciprocal

Table 2

The number of genes in the basal expression bins for the human CD4+ cell data

\begin{tabular}{lccccccc}
\hline & \multicolumn{7}{c}{ Basal expression $\left(\log _{2}\right) *$} \\
\cline { 2 - 8 } & $\mathbf{3}$ to $\mathbf{4}$ & $\mathbf{4}$ to $\mathbf{5}$ & $\mathbf{5}$ to $\mathbf{6}$ & $\mathbf{6}$ to $\mathbf{7}$ & $\mathbf{7}$ to $\mathbf{8}$ & $\mathbf{8}$ to $\mathbf{9}$ & $\mathbf{9}$ to $\mathbf{1 0}$ \\
\hline Primary & 25 & 28 & 26 & 47 & 66 & 77 & 61 \\
Secondary & 82 & 110 & 80 & 104 & 131 & 132 & 122 \\
Unchanged & 493 & 272 & 76 & 39 & 41 & 45 & 26 \\
\hline
\end{tabular}

*Genes were placed into bins according to their basal expression (robust multichip average Log $_{2}$ ) values in human primary CD4+ lymphocytes. tGenes were classified according to the kinetics of their response to P/l stimulation in EL-4 cells and their requirement for new protein synthesis. 


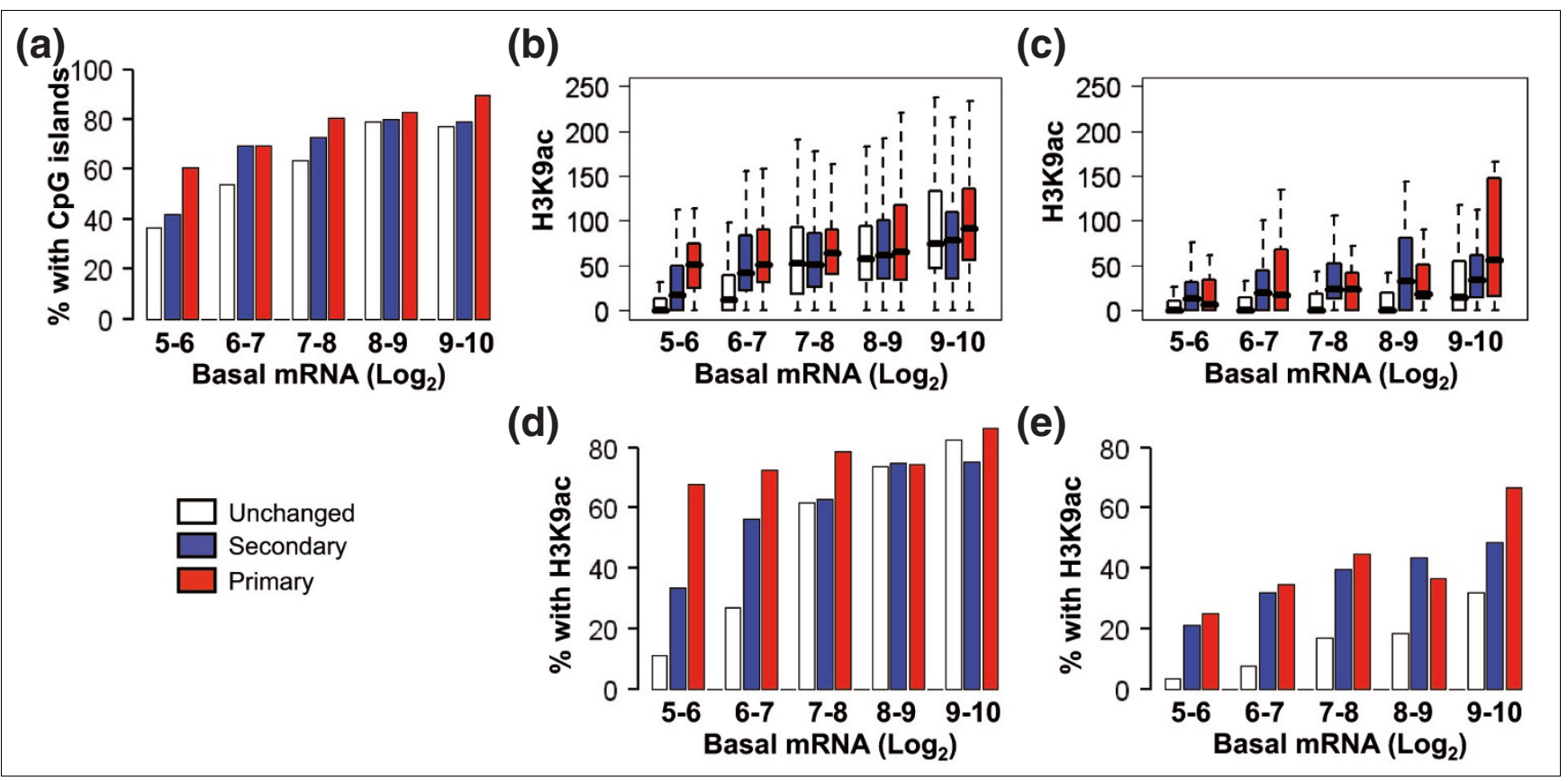

Figure 2

Higher $\mathrm{H} 3 \mathrm{~K} 9 \mathrm{ac}$ on inducible genes is independent of the presence of $\mathrm{CP}_{\mathrm{P}}$ islands. (a) The percentage of genes with $\mathrm{C}_{\mathrm{pG}}$ islands is plotted for genes grouped by their kinetics of expression (red, primary response genes; blue, secondary response genes; white, unchanged genes) and basal expression levels ( $\log _{2}$ robust multichip average values from the expression microarrays). (b, c) H3K9ac MAT scores were plotted for the different gene groups subdivided into genes with (b) or without (c) CpG islands. The bar marks the median score, the edges of the boxes the second and third interquartile ranges and the whiskers the first and fourth interquartile ranges. (d, e) The percentage of promoters with a H3K9ac MAT score $>35.2$ (FDR $<5 \%$ ) was plotted for the different groups subdivided into genes with (d) or without (e) CpG islands.

pattern across the range of expression bins, with $\mathrm{H}_{3} \mathrm{~K} 4 \mathrm{me} 3$ being strongest for the highest expression bins and $\mathrm{H}_{3}$ K27me3 strongest for the lowest expression bins (Figure 3a, b). The permissive $\mathrm{H}_{3} \mathrm{~K} 4 \mathrm{me} 3$ mark was significantly higher for both the primary and secondary gene groups compared to the unchanged group in the $\log _{2} 3$ to 4,4 to 5 and 5 to 6 basal expression bins (Figure 3a; Additional data file 7) while $\mathrm{H}_{3} \mathrm{~K} 27 \mathrm{me} 3$ displayed a reciprocal pattern across these expression bins with the exception of the secondary response genes in the lowest expression bin (Figure 3b; Additional data file 7). While the $\mathrm{H}_{3} \mathrm{~K}_{4} \mathrm{me} 1$ and me2 patterns were very similar to the $\mathrm{H}_{3} \mathrm{~K}_{4}$ me3 pattern and the $\mathrm{H}_{3} \mathrm{~K}_{2} 7 \mathrm{me} 2$ and me3 patterns resembled each other and were reciprocal to the $\mathrm{H}_{3} \mathrm{~K}_{4}$ marks, the $\mathrm{H}_{3} \mathrm{~K} 27 \mathrm{me}$ mark displayed a pattern very similar to the $\mathrm{H}_{3} \mathrm{~K}_{4}$ marks (Additional data file $5 \mathrm{a}$-d). There was no significant difference between primary and secondary gene groups for these methylation marks.

We next verified the genome-wide findings by determining the status of these two chromatin marks on our selected gene groups. All of the primary response genes, in either the gene group selected from genome-wide data or the well known primary response gene group, displayed a high level of $\mathrm{H}_{3} \mathrm{~K}_{4} \mathrm{me} 3$ and a very low level of $\mathrm{H}_{3} \mathrm{~K} 27 \mathrm{me}_{3}$, except for Egr2 (Figure 3c, d). The secondary response genes had more vari- able levels of both marks, but in general the trend was towards lower $\mathrm{H}_{3} \mathrm{~K}_{4}$ me3 and higher $\mathrm{H}_{3} \mathrm{~K} 27$ me3 levels (Figure $3 \mathrm{c}, \mathrm{d}$ ). The constitutively active or repressed genes displayed the expected patterns except for Col11a1, where neither mark was detected. A small number of genes, notably Egr2 and Il2, displayed both active and repressive methylation marks and could be classified as potentially bivalent (Figure $3 \mathrm{~d})$.

We used clustering of all of the methylation marks and the genes in the $\log _{2} 3$ to 6 basal expression bins to ask whether primary response genes in the lower basal expression bins may be enriched for genes with a 'bivalent' mark (Figure 3e). Only a small subset of the primary response genes were identified as potentially bivalent (Figure $3 \mathrm{e}$, cluster 3 ), with the majority displaying an active profile (Figure 3e, cluster 2). The genes with potentially bivalent marks did not appear to be enriched for a specific expression bin. Cluster 1 displayed an inactive profile with enrichment for $\mathrm{H}_{3} \mathrm{~K} 27 \mathrm{me} 3$ and me2 marks (Figure 3e). In addition, it can be seen that H3K27me1 did not cluster with the $\mathrm{H}_{3} \mathrm{~K} 27 \mathrm{me} 3$ and me2 marks but was more tightly linked with the $\mathrm{H}_{3} \mathrm{~K} 4$ me marks in cluster 3 (Figure $3 \mathrm{e})$. Cluster 4 showed an interesting profile with enrichment for $\mathrm{H}_{3} \mathrm{~K}_{2} 7 \mathrm{me} 1$ but lower $\mathrm{H}_{3} \mathrm{~K}_{4}$ marks. 


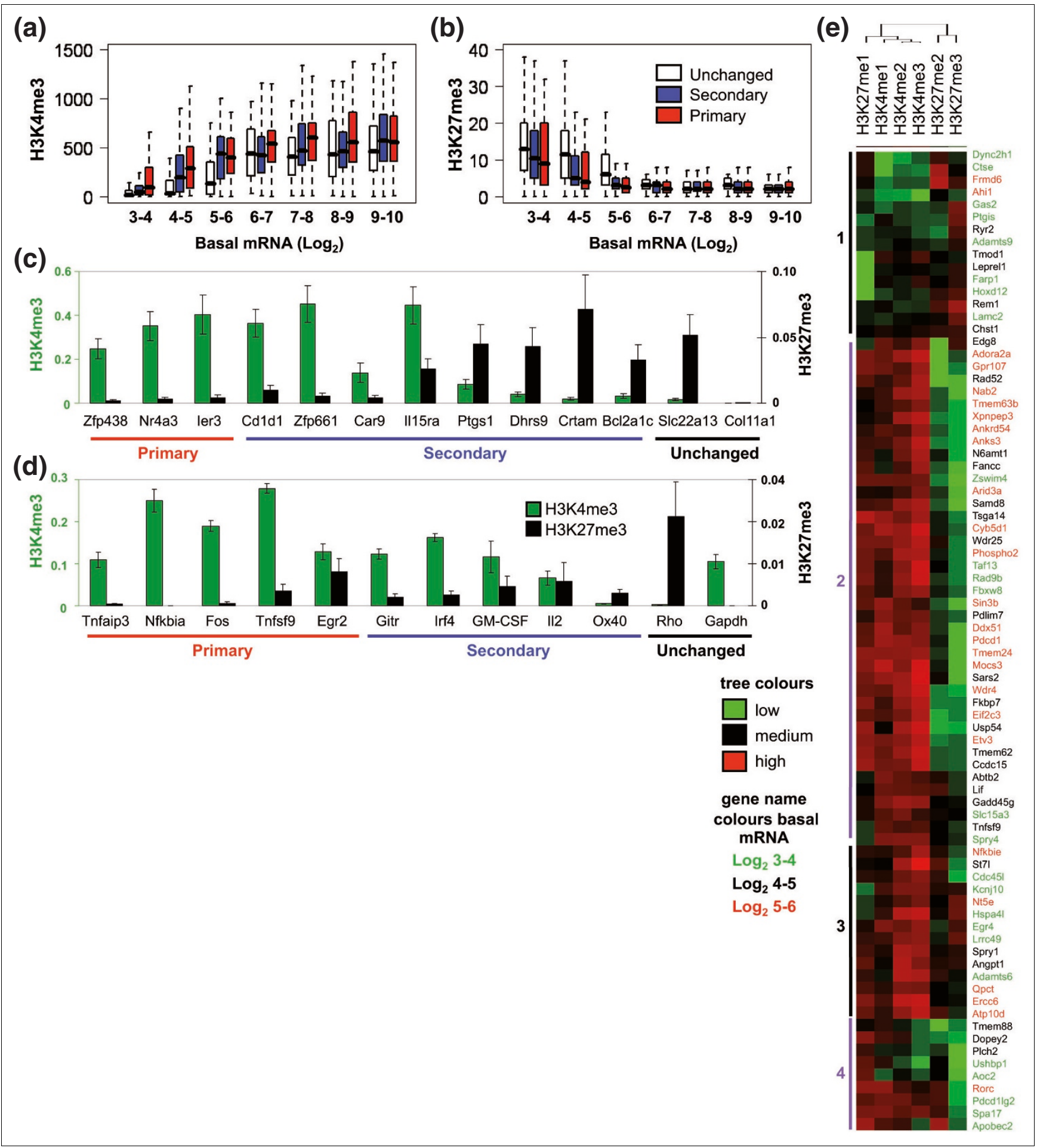

Figure 3 (see legend on next page) 
Figure 3 (see previous page)

Inducible genes have higher levels of $\mathrm{H} 3 \mathrm{~K} 4 \mathrm{me} 3$ and lower levels of H3K27me3. (a, b) Data from ChIP-Seq experiments with human CD4+ lymphocytes [28] were analyzed to determine the levels of $\mathrm{H} 3 \mathrm{~K} 4 \mathrm{me} 3$ (a) and $\mathrm{H} 3 \mathrm{~K} 27 \mathrm{me} 3$ (b) on different gene groups. The number of sequencing tags that overlapped with the promoter region $(-\mathrm{l} \mathrm{kb}$ to $+\mathrm{l} \mathrm{kb})$ of each gene was used to score the genes and the data are plotted for the genes grouped by their kinetics of response to activation (red, primary response genes; blue, secondary response genes; white, unchanged genes) and basal expression levels (Log 2 robust multichip average values from expression profiling). The bar marks the median score, the edges of the boxes the second and third interquartile ranges and the whiskers the first and fourth interquartile ranges. (c, d) ChIP was performed with antibodies against H3K4me3 (green bars) and H3K27me3 (black bars) using unstimulated EL-4 T cells and analyzed by real-time PCR, with primers designed against the promoter region. The data are presented as a ratio of immunoprecipitated DNA to total input DNA. The mean and standard error of three independent experiments are shown. (e) From the same data source used in (a) the number of sequencing tags for mono, di and tri-methylated $\mathrm{H} 3 \mathrm{~K} 4$ and $\mathrm{H} 3 \mathrm{~K} 27$, overlapping $-\mathrm{I}$ to $+\mathrm{I}$ kb from the TSS, were counted for primary response genes with basal expression values between $\log _{2} 3$ and 6 . The logs of the sequence counts were median centered and normalized and heatmaps for the primary response genes were generated by uncentered correlation, complete linkage clustering. The major clusters are marked and the genes are colored according to their basal expression level (green, $\log _{2} 3$ to 4 ; black, $\log _{2} 4$ to 5 ; red, log 5 to 6 ). In the cluster diagram green indicates low tag counts and red indicates high tag counts.

These data suggest that inducible genes are likely to be marked by active methylation marks in resting cells but that a small number may be in a bivalent state. The implications for expression response for these different gene groups are not yet clear.

\section{Inducible genes have a higher incidence of RNA polymerase II at their promoters}

Since we have shown that inducible genes with low basal mRNA expression often have an active chromatin signature, we next asked if these genes also had Pol II located at their promoters in non-stimulated cells. Using the human $\mathrm{T}$ cell ChIP-Seq data, we found that the median Pol II level was significantly higher at the promoters $(-0.25 \mathrm{~kb}$ to $+0.25 \mathrm{~kb})$ of the inducible gene groups compared with the unchanged group (Figure 4a; Additional data file 7). This was true for the primary response genes across the majority of expression bins but for the secondary response genes in the $\log _{2} 3$ to 4,4 to 5 and 5 to 6 bins. If promoters with the same or greater number of Pol II tags than the median level of Pol II for unchanged genes in the $\log _{2} 6$ to 7 basal expression bin are plotted, then a similar pattern is seen for the percentage of promoters that reach this threshold (Figure 4b; Additional data file 7). Significantly more of the primary response genes have Pol II at their promoters compared to the secondary genes in some but not all of the basal expression bins (Figure 4a, b; Additional data file 7).

We performed clustering analysis to ask if the genes with the active acetylation and methylation marks were also the genes that had Pol II at their promoters. The ChIP-Seq data from human $\mathrm{T}$ cells were used and the primary response genes in the lower basal expression bins ( $\log _{2} 3$ to 6; Table 2) were clustered. The chromatin marks used were $\mathrm{H}_{3} \mathrm{~K}_{4} \mathrm{me}_{3}$, H3K9ac, H4K16ac, H3K36ac, H2BK2Oac and H2AK9ac as active marks and $\mathrm{H}_{3} \mathrm{~K} 27 \mathrm{me} 3$ as a repressive mark. The largest cluster of these primary response genes was marked by active chromatin (Figure 4c, cluster 2); moreover, all of the genes in this cluster with an active chromatin signature also showed evidence of Pol II at their promoters. Cluster 3 contained genes that were potentially bivalent and these genes displayed lower and more variable levels of Pol II (Figure 4c). As expected, the inactive gene cluster did not display promoter Pol II (Figure 4c, cluster 1). Most importantly, there was little or no evidence for genes with Pol II but without an active or at least bivalent chromatin signature (Figure 4c).

We showed above that our selected primary response gene set, with the exception of Egr2, had relatively high levels of active chromatin marks ( $\mathrm{H}_{3} \mathrm{~K} 9 \mathrm{ac}$ and $\mathrm{H}_{3} \mathrm{~K}_{4} \mathrm{me} 3$ ) compared to the secondary response group. We therefore asked whether the primary response genes had higher levels of Pol II in the basal state compared with the secondary response genes. Figure $4 \mathrm{~d}$ shows that Pol II levels were higher on those primary response genes with an active chromatin signature (Tnfaip3, Nfkbia, Fos and Tnfsfo) and lower on Egr2 (which did not have an active chromatin signature) and also on the secondary response genes. These data support the findings from the human ChIP-Seq data clustering and again link the presence of promoter Pol II with active promoter chromatin.

Thus, we have shown that inducible genes, especially primary response genes, are more likely to have Pol II at their promoter regions and the presence of promoter Pol II is strongly associated with the presence of active chromatin marks.

\section{Elongation signatures at the transcribed regions of inducible genes}

There has been considerable interest in the nature of Pol II at gene promoters that respond to developmental or environmental signals [20-22,34]. We therefore asked whether the enrichment of Pol II at inducible gene promoters was associated with the enrichment of an elongation signature. $\mathrm{H}_{3} \mathrm{~K}_{3} 6 \mathrm{me} 3$ is a mark of elongation and can be used as an indicator of active gene transcription [35]. Hence, we examined the $\mathrm{H}_{3} \mathrm{~K}_{3} 6 \mathrm{me} 3$ elongation mark using the human $\mathrm{T}$ cell ChIP-Seq data set, and tag counting at 6 to $8 \mathrm{~kb}$ downstream of the TSS. While there was a general trend towards higher levels of $\mathrm{H}_{3} \mathrm{~K}_{3} 6 \mathrm{me}_{3}$ in the inducible genes compared with non-responsive genes, this was only statistically significant for the $\log _{2} 4$ to 5,5 to 6 and 8 to 9 basal expression bins (Figure $5 \mathrm{a}$; Additional data file 7 ), implying that these genes are 
(a)

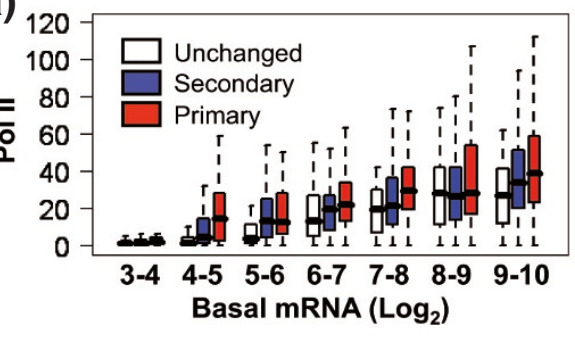

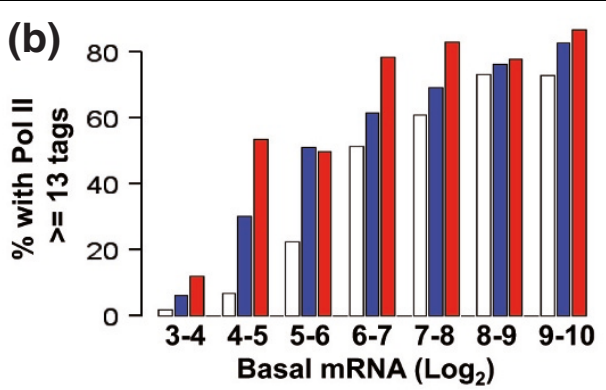

(c)

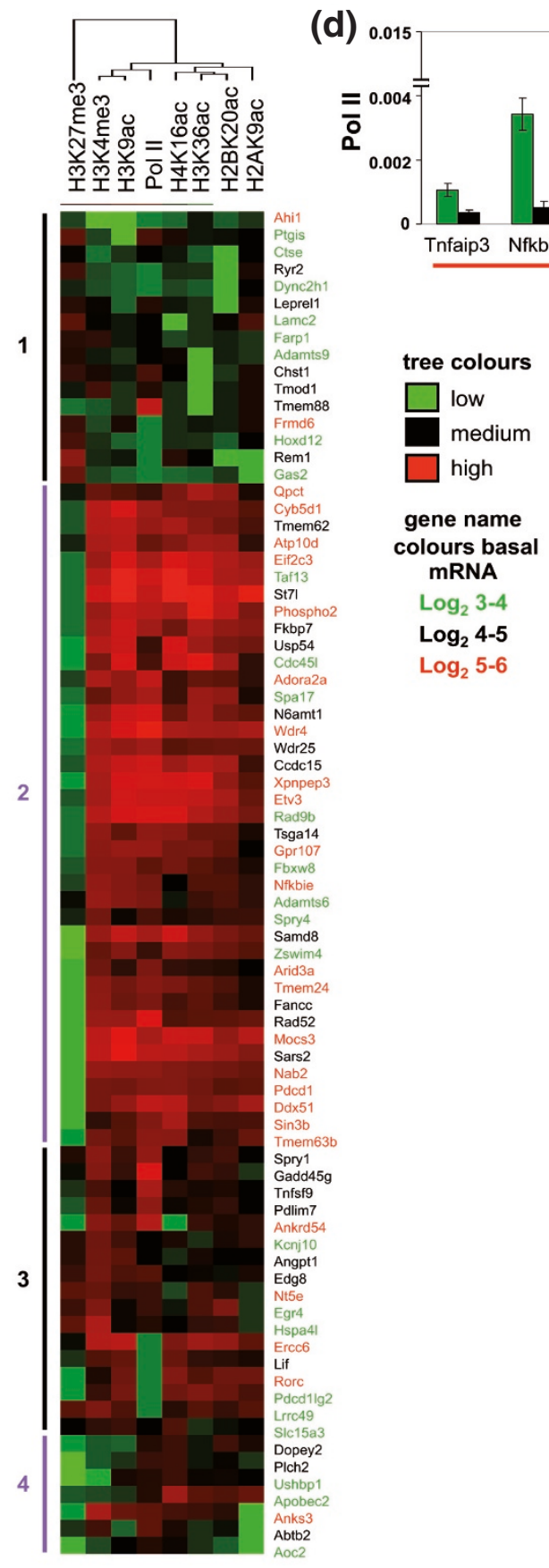

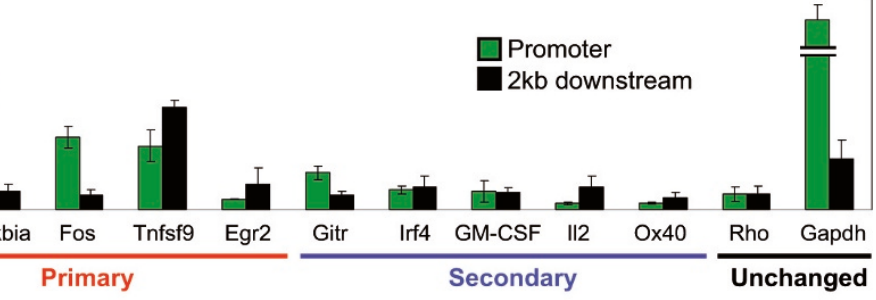


Figure 4 (see previous page)

Inducible genes have higher RNA polymerase II occupancy at promoter regions. (a) Data from ChIP-Seq experiments with human CD4+ lymphocytes was used to determine the levels of Pol II at the promoters ( $-0.25 \mathrm{~kb}$ to $+0.25 \mathrm{~kb})$ of primary (red), secondary (blue) and unchanged (white) genes within each basal expression bin ( $\log _{2}$ robust multichip average values from expression profiling). The bar marks the median score, the edges of the boxes the second and third interquartile ranges and the whiskers the first and fourth interquartile ranges. (b) The percentage of promoters with tag counts equal to or greater than the median level (I3) for the unchanged genes in the basal expression $\log _{2} 6$ to 7 bin were plotted for each subgroup. (c) From the same data source the number of sequencing tags for H3K4me3 and H3K27me27, H3K9ac, H4KI6ac, H2BK20ac, H2AK9ac and Pol II, overlapping - I to + I kb from the TSS, were counted for primary response genes with basal expression values between $\log _{2} 3$ and 6 . The logs of the sequence counts were median centered and normalized and heatmaps for the primary response genes were generated by uncentered correlation, complete linkage clustering. The major clusters are marked and the genes are colored according to their basal expression level (green, $\log _{2} 3$ to 4 ; black, $\log _{2} 4$ to 5 ; red, log 5 to 6 ). In the cluster diagram, green indicates low tag counts and red indicates high tag counts. (d) ChIP assays were performed with antibodies against the CTD repeat of Pol II using unstimulated EL-4 T cells and detected by real-time PCR analysis. The data are presented as the ratio of immunoprecipitated DNA to the total input DNA and show Pol II occupancy at the promoter (green bars) and 2 kb downstream of the promoter (black bars). The mean and standard error of three independent experiments are shown.

more likely to be undergoing elongation. If genes are considered to be $\mathrm{H}_{3} \mathrm{~K}_{3} 6 \mathrm{me} 3$ positive if they have the same number of or more tags compared with the average tag count for unchanged genes in the $\log _{2} 6$ to 7 basal expression bin, a similar pattern is seen, although the difference is only significant for primary response genes in the $\log _{2} 3$ to 4,5 to 6 and 8 to 9 bins and the $\log _{2} 4$ to 5 and 5 to 6 bins for the secondary response genes (Figure $5 \mathrm{~b}$; Additional data file 7 ). The original analysis of the ChIP-Seq data by Wang et al. [28] showed that in addition to $\mathrm{H}_{3} \mathrm{~K}_{3} 6 \mathrm{me} 3$, high levels of $\mathrm{H}_{2} \mathrm{BK}_{5} \mathrm{me} 1$ and $\mathrm{H} 4 \mathrm{~K} 2 \mathrm{Ome} 1$ occur in the coding regions of highly expressed genes. Both these marks showed a similar pattern to $\mathrm{H}_{3} \mathrm{~K}_{3} 6 \mathrm{me} 3$ in the coding regions of the inducible gene groups (Additional data file 6a, b).

Clustering analysis was used to ask whether these primary response genes with Pol II enrichment in the $\log _{2} 3$ to 6 expression bins could be divided into those with and without evidence of basal elongation. We clustered the three elongation marks described above with the Pol II signal from the human ChIP-Seq data set and found that many genes with promoter Pol II showed evidence of elongation (Figure $5 \mathrm{c}$, clusters 1 and 3 ). Cluster 3 was enriched for genes in the $\log _{2}$ 5 to 6 basal expression bin, which are thus more likely to be producing RNA transcripts in the basal state. A smaller number of genes appeared to have promoter Pol II with little or no evidence of elongation (Figure $5 \mathrm{c}$, cluster 4 ). It should be noted that $50 \%$ of the genes in cluster 4 were from the lowest expression bin ( $\log _{2} 3$ to 4 ) with only two genes from the $\log _{2} 5$ to 6 basal expression bin. Most of these genes (11 of 16) also have active promoter chromatin marks and thus most likely represent a group of poised genes with promoter enriched Pol II, active promoter chromatin but no evidence of elongation or transcript accumulation.

We examined the $\mathrm{H}_{3} \mathrm{~K}_{3} 6 \mathrm{me} 3$ levels on six genes in EL-4 T cells, three selected from cluster 3 with clearly detectable levels of this mark and three from cluster 4 with very low levels of this mark. These genes are all inducible in the EL-4 cells (data not shown). We have found that because the level of $\mathrm{H}_{3} \mathrm{~K}_{3} 6 \mathrm{me} 3$ varies from one part of the genome to another (data not shown and compare Rho with Gapdh) it is important to compare the level of this mark within the transcribed region and the promoter region of any one gene to gauge the level of enrichment within the gene. The three genes from cluster 3, Gadd45g, Nfkbie and Zswim4, all had higher levels of $\mathrm{H}_{3} \mathrm{~K}_{3} 6 \mathrm{me} 3$ in their transcribed regions compared with their promoter regions (Figure $5 \mathrm{~d}$ ). The three genes from cluster 4, Adamts6, Usp54 and Hspa41, however, did not show a significant enrichment of $\mathrm{H}_{3} \mathrm{~K}_{3} 6 \mathrm{me} 3$ in their transcribed regions compared with their promoter regions and are similar to the inactive Rho pattern, implying a lack of basal elongation (Figures $5 \mathrm{~d}$ and $6 \mathrm{~d}$ ). The selected primary gene set also displayed an enrichment of $\mathrm{H}_{3} \mathrm{~K}_{3} 6 \mathrm{me}_{3}$ in their transcribed regions with Egr2, the gene with the least promoter Pol II (Figure 4d), also having the lowest $\mathrm{H}_{3} \mathrm{~K}_{3} 6 \mathrm{me}_{3}$ enrichment (Figure 6d). Despite evidence of ongoing elongation as measured by the presence of $\mathrm{H}_{3} \mathrm{~K}_{3} 6$ me3 in their transcribed regions, these genes display low but variable levels of expression (Additional data file 3), suggesting further posttranscriptional control for at least some primary response genes.

Taken together, these data imply that primary response genes are more likely to have an elongation signature compared with their non-responsive counterparts with comparable basal expression. In addition, we identified a group of primary response genes with active promoter chromatin and promoter Pol II but no or a low number of elongation marks.

\section{Inducible genes show an increase in Pol II recruitment and elongation marks following activation}

We reasoned that if many of the inducible genes, especially the primary response genes, were already in an active chromatin configuration and had Pol II available at their promoters, there may be little or no change in the level of active chromatin marks or Pol II following stimulation. We first examined changes in $\mathrm{H}_{3} \mathrm{~K}$ 9ac genome-wide by performing ChIP-on-chip experiments with $\mathrm{H}_{3} \mathrm{~K} 9 \mathrm{ac}$ and $\mathrm{H}_{3}$ antibodies in EL- 4 cells stimulated for 0.5 or $4 \mathrm{~h}$ with $\mathrm{P} / \mathrm{I}$. Acetylation changes were assessed across $\mathrm{a}+1.2$ to $-0.6 \mathrm{~kb}$ region and genes designated as acetylated if there was a MAT score in 
(a)

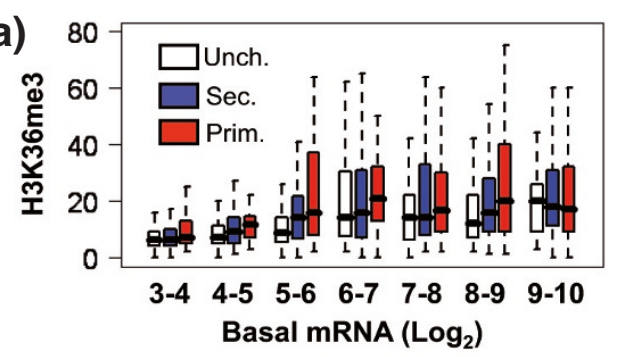

(b)

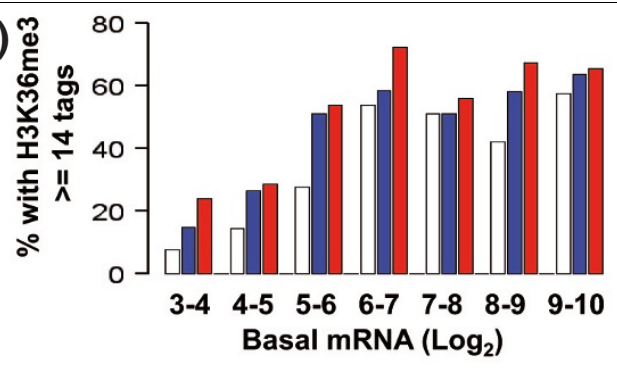

(c)

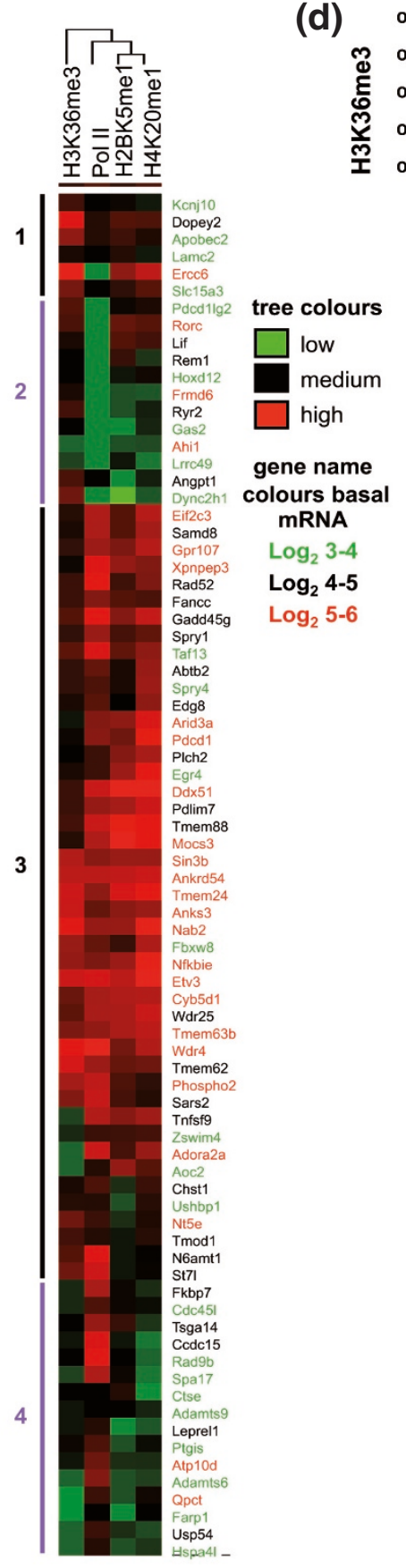

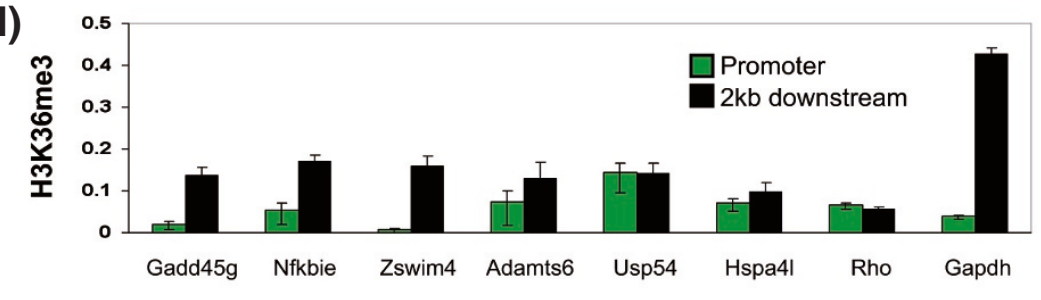


Figure 5 (see previous page)

Inducible genes have higher levels of the elongation mark H3K36me3. (a) Data from ChIP-Seq experiments on human CD4+ lymphocytes were used to determine the levels of $\mathrm{H} 3 \mathrm{~K} 36 \mathrm{me} 3$ within the gene $(+6$ to $+8 \mathrm{~kb})$ for primary (red), secondary (blue) and unchanged (white) genes in each basal expression bin (Log 2 robust multichip average values from expression profiling). The bar marks the median score, the edges of the boxes the second and third interquartile ranges and the whiskers the first and fourth interquartile ranges. (b) The genes with tag counts equal to or greater than the median level (I4) for the unchanged genes in the basal expression $\log _{2} 6$ to 7 bin were considered to have $\mathrm{H} 3 \mathrm{~K} 36 \mathrm{me} 3$, and the percentage of genes that were $\mathrm{H} 3 \mathrm{~K} 36 \mathrm{me} 3$ positive for each subgroup is shown. (c) From the same data source the number of sequencing tags for Pol II (-0.25 kb to $+0.25 \mathrm{~kb})$ and the putative elongation marks $\mathrm{H} 2 \mathrm{BK} 5 \mathrm{mel}(0$ to $+2 \mathrm{~kb})$ and $\mathrm{H} 4 \mathrm{~K} 20 \mathrm{mel}(0$ to $+7.5 \mathrm{~kb})$ as well as $\mathrm{H} 3 \mathrm{~K} 36 \mathrm{me} 3$ were counted for genes with basal expression values between $\log _{2} 3$ and 6 . The logs of the sequence counts were median centered and normalized and heatmaps for the primary response genes were generated by uncentered correlation, complete linkage clustering. The major clusters are marked and the genes are colored according to their basal expression level (green, $\log _{2} 3$ to 4 ; black, $\log _{2} 4$ to; red, $\log _{2} 5$ to 6 ). In the cluster diagram green indicates low tag counts and red indicates high tag counts. (d) ChIP assays were performed with antibodies against trimethylated $\mathrm{H} 3 \mathrm{~K} 36$ ( $\mathrm{H} 3 \mathrm{~K} 36 \mathrm{me} 3)$ using unstimulated EL-4 T cells and detected by real-time PCR analysis. The data are presented as the ratio of immunoprecipitated DNA to the total input DNA and shows H3K36me 3 occupancy at the promoter (green bars) and $2 \mathrm{~kb}$ downstream of the promoter (black bars). The mean and standard error of three independent experiments are shown.

this region of $>35.2(\mathrm{FDR}<0.1)$. We found that in the lower basal expression bins ( $\log _{2} 4$ to 6 ), while $25 \%, 12 \%$ and $3 \%$ of the primary, secondary and unchanged gene groups, respectively, were acetylated in the unstimulated cells, only $3 \%$ (two genes) of the promoters of primary response genes became transiently acetylated at $0.5 \mathrm{~h}$ following activation and 5\% (14 genes) of the secondary response genes were newly acetylated at $4 \mathrm{~h}$ compared with $0.2 \%$ (12 and 13 genes at $0.5 \mathrm{~h}$ and $4 \mathrm{~h}$, respectively) of the unchanged genes (data not shown). These data imply that the vast majority of inducible genes do not show an increase in $\mathrm{H}_{3} \mathrm{~K} 9 \mathrm{ac}$ in response to activation and may already be sufficiently acetylated for downstream events to occur.

We next examined $\mathrm{H}_{3} \mathrm{~K} 9 \mathrm{ac}$ levels in the selected group of inducible genes following stimulation of EL-4 T cells with P/ I. Only Egr2, which had low H3K9ac levels in unstimulated cells, showed consistent evidence of an increase in $\mathrm{H}_{3} \mathrm{~K} 9 \mathrm{ac}$ following activation (Figure 6a). These results are in agreement with our previous studies showing that there was no increase in $\mathrm{H}_{3} \mathrm{~K}$ 9ac or other acetylation marks at the promoter regions of the Il2 and GM-CSF genes [29]. These results also agree with the genome-wide ChIP-on-chip studies described above where only a small percentage of genes showed an increase in acetylation. In addition, we did not detect any significant increases in the active methylation mark $\mathrm{H}_{3} \mathrm{~K}_{4}$ me3 (data not shown) as mentioned in the work by Roh et al. [25].

These data imply that increases in acetylation or active methylation marks are not an essential component of gene activation and that some genes may already be in a sufficiently active chromatin state to allow transcription in response to appropriate signals.

We next determined the changes in Pol II both at the promoter and in the transcribed regions of the selected gene set. For all of the primary response genes, despite detectable levels of Pol II at the majority of the promoters in non-stimulated cells, there was an immediate increase in Pol II at the promoter and an accompanying but smaller increase in the transcribed regions (Figure 6b). In the secondary response group, only three genes, Irf4, Gitr and Il2, showed detectable increases in Pol II and these increases appeared later, in keeping with the delayed expression of these genes (Figure $6 \mathrm{~b}$; Additional data file 3). The inability to detect Pol II on some secondary response genes may relate to the affinity of the antibody coupled with the degree of induction.

Additionally, we examined Pol II recruitment to two genes from the cluster analysis in Figure 5c (Gadd45g from cluster 3 with evidence of basal elongation and Adamts 6 from cluster 4 with evidence for a poised polymerase) and an additional constitutively active control gene, $R p l_{3}$, in an independent set of quantitative PCR experiments. Both Gadd $45 \mathrm{~g}$ and Adamts6, despite their different basal states, showed evidence of Pol II recruitment at the promoter and an accompanying but lesser increase in the transcribed region while Pol II levels on $\mathrm{Rpl}_{3}$, like those on Gapdh, were not changed (Figure 6c). Tnfaip3, Fos and Tnfsfs behaved in a similar manner in the two independent experimental sets (Figure 6b, c).

For most genes, with the exception of $I l 2$ and $\operatorname{Tnf} f f g$, the level of Pol II in the transcribed regions of the genes was significantly lower than at the promoter (Figure 6b), making it difficult to assess whether promoter recruitment of Pol II leads to an increase in elongation. We therefore assessed the level of $\mathrm{H}_{3} \mathrm{~K}_{3} 6 \mathrm{me} 3$ at the promoter and the transcribed regions of the genes. In non-stimulated cells, the level of $\mathrm{H}_{3} \mathrm{~K}_{3} 6 \mathrm{me}_{3}$ was higher in the transcribed regions than at the promoter for all genes examined, implying, in agreement with the genomewide results above, that there may be some basal transcription occurring from these genes before activation (Figure 6d). Following activation, all of the genes that had an increased recruitment of Pol II to their promoters also underwent an increase in $\mathrm{H}_{3} \mathrm{~K}_{3} 6 \mathrm{me} 3$ levels in the transcribed region of the genes (Figure 6d). In addition, several other secondary response genes also showed increased $\mathrm{H}_{3} \mathrm{~K}_{3} 6 \mathrm{me} 3$ following activation (Figure 6d), implying that either a promoter region other than that examined was being used or that Pol II antibody was not as sensitive as the $\mathrm{H}_{3} \mathrm{~K}_{3} 6 \mathrm{me} 3$ antibody. 


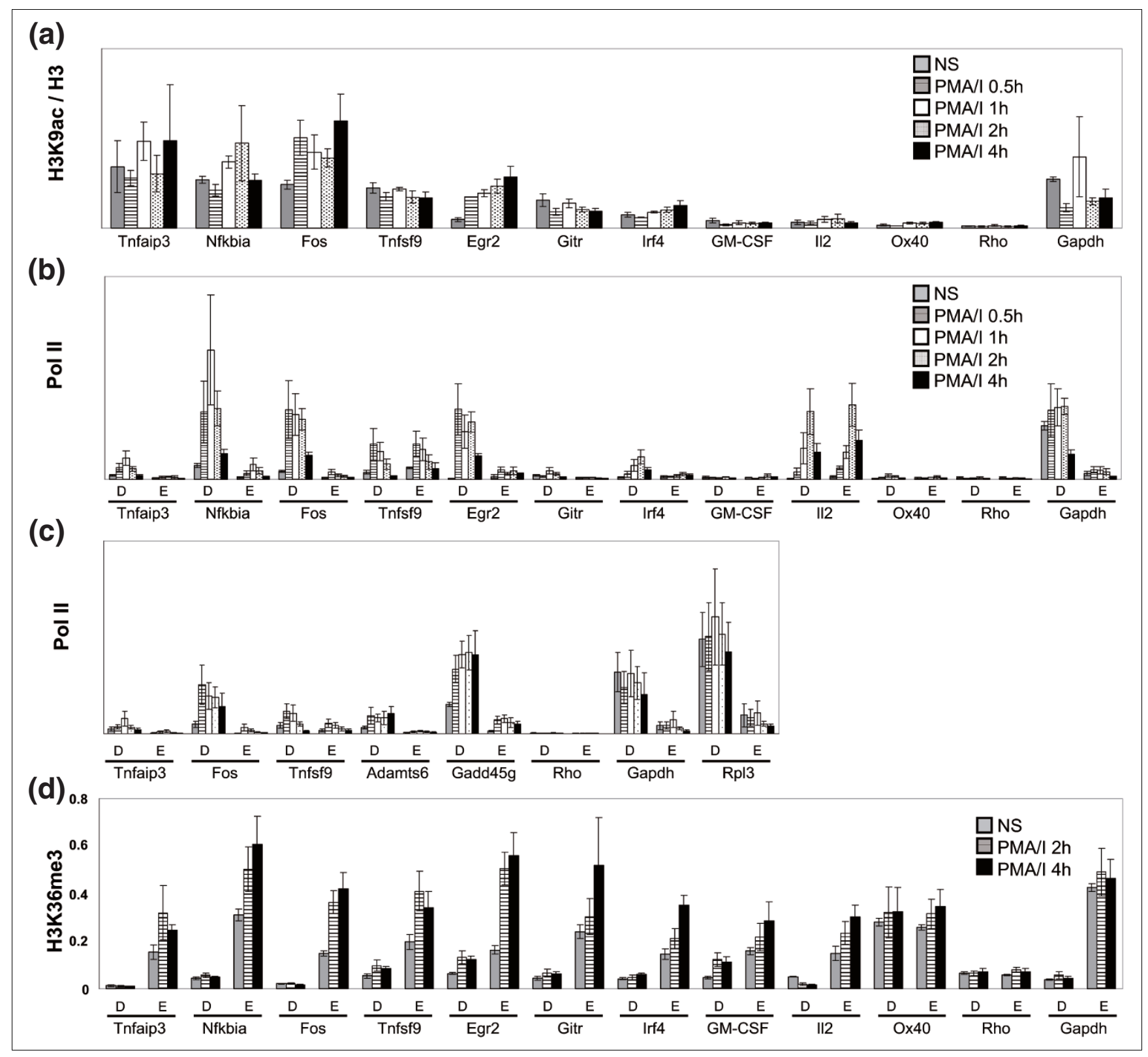

Figure 6

Changes in $\mathrm{H} 3 \mathrm{~K} 9 \mathrm{ac}$, Pol II and H3K36me3 upon stimulation of EL-4 T cells. (a) ChIP assays were performed with antibodies against H3K9ac using unstimulated EL-4 T cells (grey bars), and cells that were stimulated with P/l for $0.5 \mathrm{~h}$ (hatched bars), I h (white bars), $2 \mathrm{~h}$ (dotted bars) and $4 \mathrm{~h}$ (black bars). The data for the promoter region of each gene are presented as a ratio of $\mathrm{H} 3 \mathrm{~K} 9 \mathrm{ac} / \mathrm{H} 3$ levels. The mean and standard error of at least three independent experiments are shown. (b, c) ChIP was performed with antibodies against the CTD repeat of Pol II using unstimulated EL-4 T cells (grey bars), and cells that were stimulated with $\mathrm{P} / \mathrm{l}$ for $0.5 \mathrm{~h}$ (lined bars), I $\mathrm{h}$ (white bars), $2 \mathrm{~h}$ (dotted bars) and $4 \mathrm{~h}$ (black bars). The data are presented as a ratio of immunoprecipitated DNA to the total input DNA and show Pol II occupancy for the promoter region (primer set D) and $2 \mathrm{~kb}$ downstream of the TSS (primer set E). The mean and standard error of three independent experiments are shown for each primer set. (d) A ChIP assay was performed with antibodies against H3K36me3 using unstimulated EL-4 T cells (grey bars), and cells that were stimulated with P/l for $2 \mathrm{~h}$ (lined bars) and $4 \mathrm{~h}$ (black bars). The data are presented as ratios of immunoprecipitated DNA to the total input DNA and shows H3K $36 \mathrm{me} 3$ occupancy at the promoter region (primer set $D$ ) and $2 \mathrm{~kb}$ downstream (primer set $\mathrm{E}$ ). The mean and standard error of four independent experiments are shown. PMA, phorbol myristate acetate. 
These data suggest that while inducible genes, in particular primary response genes, may be in an active chromatin configuration and have varying levels of Pol II at their promoters in non-stimulated cells, they still recruit more Pol II and increase their rate of elongation, as measured by increased $\mathrm{H}_{3} \mathrm{~K}_{3} 6 \mathrm{me} 3$, contributing to the observed increases in mRNA levels.

\section{Discussion}

We have used several approaches to show that, in non-stimulated T cells, inducible genes with lower basal mRNA expression are more likely than their non-responsive counterparts to have an active chromatin signature. This active signature is particularly pronounced for primary response genes. In addition, the presence of this active chromatin signature on a gene is strongly associated with the co-location of Pol II at the gene promoter. A subgroup of genes with an active chromatin signature and promoter Pol II appear to be in a poised state.

Many studies to date, either on individual genes [29,36-38] or genome-wide [17,25,26,33,39-41], have clearly shown that chromatin around active genes is highly acetylated as well as trimethylated at $\mathrm{H}_{3} \mathrm{~K}_{4}$. Recent ChIP-Seq studies in human CD4+ T cells have identified a chromatin signature for active genes, including acetylation at a number of lysine residues, and mono-, di-, and trimethylation on $\mathrm{H}_{3} \mathrm{~K}_{4}[24,28]$. We show here that a similar chromatin signature marks not only active genes but also inducible genes, especially primary response genes, and the enrichment of these marks distinguishes them from their non-responsive counterparts with similar basal expression levels, especially in the lower basal expression bins. Very recently, a similar active chromatin signature has been found on many primary response genes in macrophages [42]. Hargreaves at al. [42] also showed that their primary response gene group displayed active chromatin marks in several cell types, including embryonic stem cells, and suggested that primary response genes that respond to a variety of signals in many cell types may be tagged in this manner at a very early stage of development. We have also found that our primary response gene set is tagged with active chromatin in macrophages and B cells (data not shown), supporting the data of Hargreaves et al [42], whereas the secondary response genes that showed cellspecific expression were more variable (data not shown).

Clustering analysis clearly demonstrated that Pol II was associated with the same sets of genes that had an active chromatin signature. We found little or no evidence for the presence of an active chromatin signature in the absence of Pol II or vice versa. The small numbers of genes with such a signature are likely to have alternative TSSs. It is generally accepted that histone modifying complexes are recruited to specific genomic regions through their interaction with transcription factors that recognize their cognate DNA binding sites (reviewed in [1]). The components of the Pol II initiation com- plex, likewise, are recruited by directly or indirectly interacting with transcription factors bound to promoter regions [4345]. Our results support a model of co-recruitment of histone modifying complexes and the Pol II complex since they appear to be collocated on the majority of promoters. Indeed, many transcription factors have been shown to interact with both components of the Pol II initiation complex and with histone modifying complexes (reviewed in [46]) and so corecruitment by the same complexes is one possible model. A recent study has shown a possible role for the transcription factor $\mathrm{Sp} 1$ in the maintenance of an active chromatin state and the promoter enrichment of Pol II in primary response genes in macrophages [42]. This characteristic was associated with primary response genes with GC-rich promoter regions [42], and others have also recently shown that GC richness may be an important feature of establishing the permissive chromatin structure of inducible genes [47]. However, we found here that although GC-rich promoters clearly have higher levels of active chromatin marks and promoter Pol II than their non-GC-rich counterparts, the difference between the primary response genes and the non-responsive genes in a given expression bin was evident for both genes with GCrich promoters and those with non-GC-rich promoters.

Only a small subset of the primary response genes was potentially 'bivalent', having both $\mathrm{H}_{3} \mathrm{~K}_{4} \mathrm{me}_{3}$ and $\mathrm{H}_{3} \mathrm{~K}_{2} 7 \mathrm{me}_{3}$ on the same gene. These genes generally had promoter Pol II but, in general, the Pol II levels were lower and more variable than those of the genes with only active marks. The potentially bivalent genes did not display a clear pattern of active elongation marks and were not associated with either the poised or actively elongating gene sets (data not shown). Perhaps for most primary response inducible genes the permissive chromatin state is established more by the presence of other active histone modifications like $\mathrm{H}_{3} \mathrm{~K} 9 \mathrm{ac}$, as shown in a study on CD8+ $\mathrm{T}$ cells [9], than by bivalency because of the need to respond rapidly to extracellular signals. The enrichment of active chromatin marks and promoter Pol II and the finding by others of nucleosome depletion [27] on inducible genes in non-stimulated cells suggests that the promoters of these genes resemble those of active genes regardless of the level of mature mRNA in the basal state.

Several recent genome-wide studies in yeast and Drosophila have shown that Pol II is located at the promoters of large numbers of genes that respond to environmental or developmental signals $[17,18,20,21,24,25,28,39,48]$. These studies, and others on single genes [49,50], have led to the identification of a group of genes that are described as poised and potentially active $[14,22,34,51]$. Our data clearly show, in agreement with these studies, that inducible genes, especially primary response genes, are more likely to have Pol II at their promoters than their non-responsive counterparts with comparable expression levels. Even within the lowest basal expression bin ( $\log _{2} 3$ to 4 ) in the human T cell data set, $>65 \%$ of the genes had evidence of promoter Pol II. 
The primary response genes from the $\log _{2} 3$ to 6 basal expression bins with promoter Pol II fell into two distinct categories; those with and without evidence of elongation. The clusters with evidence of elongation are clearly enriched for genes from the higher expression bins (64\% of the $\log _{2} 4$ to 5 genes and $77 \%$ of the $\log _{2} 5$ to 6 genes fall into cluster 3 in Figure $5 \mathrm{c}$ ). This suggests that many primary response genes are already producing mRNA and induction leads to an increase from that basal level. Many of the independently assessed genes, such as Tnfaip3, Nfkbia, Fos and Tnfsf9, also display evidence of ongoing elongation in the basal state. These genes all display low but variable levels of mRNA, implying that there may be control of mRNA accumulation or stability posttranslationally, as has previously been shown for genes such as Fos [52]. While the gene cluster with the strongest elongation signature (cluster 3 in Figure $5 \mathrm{c}$ ) is clearly enriched for genes that are more highly expressed in the basal state $\left(\log _{2} 5\right.$ to 6), there are also genes in this cluster with lower expression levels (for example, Taf13, Spry4), in which post-translational events may also play a role.

Only a relatively small cluster of genes (cluster 4 in Figure $5 c$ ) displayed promoter Pol II but had little or no evidence of elongation, and these genes were generally represented in the lowest basal expression bin. Most of these genes (11 of 16) also had an active histone acetylation and methylation signature. It is likely that such genes possess a strong signal for Pol II pausing, but further experiments would be required to determine the nature of that pausing signal. Some factors involved in the pausing of Pol II are the Negative elongation factor (NELF) and also DSIF (5,6-dichloro-1-beta-D-ribofuranosylbenzimidazole (DRB)-sensitivity-inducing factor), both of which have been shown to have repressive effects on Pol II elongation [23]; these factors have previously been shown to operate in T cells [53].

All of the primary response genes that we assessed, whether showing evidence of basal elongation or not, recruited more Pol II and displayed evidence of increased elongation following gene activation. These results imply that while the genes may have some level of Pol II and $\mathrm{H}_{3} \mathrm{~K}_{3} 6$ me3 in the nonstimulated cells, activation leads to an increase in these activities, most likely brought about by the induction of inducible transcription factors that more efficiently recruit and activate Pol II. Many inducible genes in T cells are controlled by inducible transcription factors such as AP-1 and NF- $\mathrm{BB}$, all of which have been shown to play a role in Pol II recruitment and or elongation $[42,54]$. We found little evidence, however, for an increase in $\mathrm{H}_{3} \mathrm{~K}$ 9ac following activation and postulate that many inducible genes already display an active chromatin configuration that does not require further alteration for increased gene activity. Hargreaves et al. [42] have recently proposed a model whereby constitutive transcription factors such as Sp1 recruit certain histone acetylases, such as p30o, to primary response genes to maintain an active chromatin acetylation signature. Inducible transcription factors then recruit different acetylases that modify a different set of lysines on the histone proteins to provide a platform to generate an even more active gene. It would be of interest to examine these latter histone modifications in T cells.

\section{Conclusions}

The results presented here show that inducible genes, especially primary response genes, are in a more active chromatin state than their non-responsive counterparts for a given basal expression level. Recent evidence suggests that the permissive state of primary response genes may be present throughout development to allow rapid expression of these genes in many cell types [42]. It will be important to determine the molecular mechanisms that initiate and maintain this permissive state.

\section{Materials and methods \\ Cell culture}

All reagents were from Sigma-Aldrich (St Louis, MO, USA) unless otherwise stated. EL-4 T cells were cultured in RPMI 1640 medium with $10 \mathrm{mM}$ HEPES, 10\% fetal calf serum (CSL, Parkville, Victoria, Australia), $120 \mu \mathrm{g} / \mathrm{ml}$ penicillin, and 16 $\mu \mathrm{g} / \mathrm{ml}$ gentamycin. Cells were pretreated with $10 \mu \mathrm{g} / \mathrm{ml} \mathrm{CHX}$ for 30 minutes, and then stimulated with $10 \mathrm{ng} / \mathrm{ml}$ phorbol myristate acetate (Boehringer Mannheim, Mannheim, Germany) and $1 \mu \mathrm{M}$ ionomycin (I; Sigma-Aldrich).

\section{RNA isolation and quantitative PCR}

Total RNA was isolated using TRI-reagent, reverse transcribed as previously described and quantitative PCR (qPCR) amplification was performed with SYBR Green as previously described [55]. Amplifications were performed in 384-well optical reaction plates (Applied Biosystems, Foster City, CA, USA) with a 7900 HT Fast Real-Time PCR System (at the ACRF Biomolecular Resource Facility, JCSMR, ANU) using SDS 2.2.2 software to analyze raw data. For mRNA expression, relative mRNA levels were calculated by normalizing $\mathrm{Ct}$ values to ubiquitin-conjugating enzyme E2D 2 ( UBC) Ct values. For ChIP analysis, relative values were calculated by normalizing immunoprecipitated DNA to total input genomic DNA with subtraction of the no-antibody background. Primers used for ChIP assay detection were designed against the promoter region and $2 \mathrm{~kb}$ downstream of the TSS.

\section{ChIP assay}

ChIP assays were performed as previously described with some modifications [29]. Briefly, cells were harvested and crosslinked with formaldehyde. Cells were lysed and then sonicated using the Bioruptor (Diagenode, Liege, Belgium) to give fragments between $200 \mathrm{bp}$ and 1,00o bp in length. Samples were pre-cleared with protein-A agarose/salmon sperm DNA beads (Upstate, Lake Placid, New York, USA) then immunoprecipitated with $2.5 \mu \mathrm{g}$ anti-histone-H3 (Abcam, Cambridge, UK), $4 \mu \mathrm{g}$ anti-acetyl-H3K9 (Upstate), $2 \mu \mathrm{g}$ anti- 
trimethyl-H3K4 (Abcam), $8 \mu \mathrm{g}$ anti-trimethyl-H3K27 (Upstate), $4 \mu \mathrm{g}$ anti-trimethyl-H3K36 (Abcam), and $6 \mu \mathrm{g}$ of anti-RNA polymerase II CTD repeat (Abcam, ab817).

\section{Expression microarrays}

Three biological replicates for each treatment were carried out for the expression profiling experiments. Affymetrix Mouse Gene 1.oST arrays were used as per the manufacturer's instructions. Quantile normalization and robust multichip average (RMA) background correction adjusting for probe sequence (Partek Software, St. Louis, Missouri, USA) was used to generate gene expression levels from the Mouse Gene 1.oST arrays and an ANOVA test was used to identify genes induced or not induced ('unchanged') with P/I stimulation. Primary response genes were identified as genes with significantly $(P<0.016$ equivalent to a FDR $<0.1)$ higher expression in $\mathrm{P} / \mathrm{I}$-stimulated cells than in unstimulated cells and these genes also had to have higher or equal expression in CHXtreated P/I-stimulated cells than in just P/I-stimulated cells; that is, genes whose expression increased with stimulation and the increase was not inhibited by CHX. Secondary response genes were identified as genes with significantly $(P$ $<$ o.016) higher expression in stimulated cells (than unstimulated), whose expression was also significantly $(P<0.024$, FDR < 0.1 ) decreased in the CHX-treated P/I-stimulated cells compared to the $\mathrm{P} / \mathrm{I}$ stimulated cells; that is, genes where expression increased with stimulation and the increase was inhibited by CHX. Genes with $P$-values $>0.1$ for all factors were classified as unchanged genes. Only genes whose promoter was represented on the DNA tiling array were used for further analysis. Groups were then subdivided further depending on their average basal expression level. Raw and normalized data have been deposited in the NCBI Gene Expression Omnibus (GEO) under accession number [GEO:GSE13278].

\section{DNA promoter microarrays}

ChIP DNA was amplified with the Whole Genome Amplification kit from Sigma as per the manufacturer's instructions but with incorporation of dUTP. DNA was fragmented and hybridized to Affymetrix Mouse Promoter 1.oR arrays as per the standard Affymetrix protocol. Three biological replicates were used for data for unstimulated cells and for the effects of stimulation on $\mathrm{H}_{3}$ K9ac levels two replicates each for o-h, o.5$\mathrm{h}$ and 4-h stimulation were used.

\section{ChIP-on-chip data analysis}

All analysis was performed with NCBI build 36 of the mouse genome. The MAT algorithm [30] was used to find regions of $\mathrm{H}_{3} \mathrm{~K} 9 \mathrm{ac}$ with a bandwidth of $250 \mathrm{bp}$ and a maximum gap of 150 bp. Either the matching total input DNA or $\mathrm{H}_{3}$ values were used as control samples. A MAT ( $-10 \log$ p value) region cutoff score of $>35.2$ corresponds to a FDR $<0.05$ when three replicates were used (for analysis in unstimulated cells) and a FDR <0.1 when two replicates were used (for analysis of changes with stimulation). The same parameters were used to detect regions of antibody non-specific binding using the noantibody sample arrays. Raw and normalized data have been deposited in GEO under accession number [GEO:GSE13277].

The TSSs for the genes on the 1.0ST array were obtained from the Affymetrix annotation file for build 36. Duplicate genes were not removed as often they represented pseudo-genes on different chromosomes. There is minimum gene duplication on the 1.oST array and preliminary analysis indicated that removal of replicates does not affect results. $\mathrm{R}$ was used to detect if the regions of $\mathrm{H}_{3} \mathrm{~K} 9 \mathrm{ac}$ overlapped with the promoters of the genes in the expression groups. Where more than one region overlapped with a gene promoter, the region with the highest score was used. The promoter was considered to be from $-1.2 \mathrm{~kb}$ (upstream) to $+0.6 \mathrm{~kb}$ (downstream) of the TSS. Either Wilcoxon rank or Fisher exact tests were used to determine statistical significance (using R).

\section{ChIP-Seq analysis}

Genome-wide ChIP-Seq data were obtained from Wang et al. [28] and the matching expression data were downloaded from GEO [GEO:GSE10437]. The raw expression data were normalized using RMA normalization (with the Partek software) as described above as opposed to the original GCOS/ MAS5 normalization used in the original paper. The gene coordinates for the human orthologs of the mouse genes were obtained using BIOMART. R was used to count the number of sequencing tags overlapping the regions of interest. For clustering, the logs of the sequence counts for the primary, secondary and unchanged genes with basal expression values $\log _{2} 3$ to 6 were median centered and normalized using the Cluster software (Stanford). Heatmaps were generated by uncentered correlation, complete linkage clustering and viewed with TreeView (Stanford).

\section{Abbreviations}

ChIP: chromatin immunoprecipitation; ChIP-on-chip: ChIP combined with microarray technology; ChIP-qPCR: ChIP with quantitative PCR; ChIP-Seq: ChIP with massively parallel sequencing; CHX: cycloheximide; FDR: false discovery rate; GEO: Gene Expression Omnibus; MAT: model-based analysis of tiling array; P/I: phorbol 12-myristate 13-acetate and ionomycin; Pol II: RNA polymerase II; qPCR: quantitative PCR; RMA: robust multichip average; TSS: transcriptional start site.

\section{Authors' contributions}

PL carried out the experimental studies and drafted the manuscript. $\mathrm{KH}$ carried out the data mining and analysis and drafted the manuscript. $\mathrm{KB}$ and $\mathrm{CX}$ are responsible for the preliminary studies that contributed to the conception of the study. LM prepared ChIP samples for ChIP-on-chip studies. PK carried out the microarray experiments. MS conceived the study and participated in its design and coordination and 
drafted the manuscript. All authors read and approved the final manuscript.

\section{Additional data files}

The following additional data are available with the online version of this paper: a figure of the density plot of basal expression values for different gene groups and the MAT score from no antibody ChIP-on-chip arrays (Additional data file 1); a figure of ChIP with $\mathrm{H}_{3}$ and $\mathrm{H}_{3} \mathrm{~K} 9 \mathrm{ac}$ in unstimulated EL-4 cells (Additional data file 2); a figure of mRNA expression levels of genes in the gene-focused studies (Additional data file 3); a figure of data mined from human $\mathrm{CD}_{4}+\mathrm{ChIP}-$ seq experiments for H2AK9ac, H2BK2Oac, $\mathrm{H}_{3} \mathrm{~K}_{3} 6 \mathrm{ac}$ and $\mathrm{H}_{4} \mathrm{~K} 16 \mathrm{ac}$ (Additional data file 4); a figure of data mined from human $\mathrm{CD}_{4}+$ ChIP-seq experiments for $\mathrm{H}_{3} \mathrm{~K} 4 \mathrm{me} 2$, $\mathrm{H}_{3} \mathrm{~K}_{4} \mathrm{me} 1, \mathrm{H}_{3} \mathrm{~K} 27 \mathrm{me} 2$ and $\mathrm{H}_{3} \mathrm{~K}_{27 m e 1}$ (Additional data file 5); a figure of data mined from human CD4+ ChIP-seq experiments for $\mathrm{H}_{4} \mathrm{~K}_{2} \mathrm{Ome} 1$ and $\mathrm{H}_{2} \mathrm{BK}_{5} \mathrm{me} 1$ (Additional data file 6); a table of the $P$-values for the epigenomic marks in the different basal expression groups (Additional data file 7).

\section{Acknowledgements}

We wish to thank Drs Adele Holloway, David Tremethick and Stephen Smale for useful discussions, and Dr Rohan Williams and Hugh French for assistance with $\mathrm{R}$ programming.

\section{References}

I. Kouzarides T: Chromatin modifications and their function. Cell 2007, I 28:693-705.

2. Li B, Carey M, Workman JL: The role of chromatin during transcription. Cell 2007, I 28:707-7I9.

3. Tremethick DJ: Higher-order structures of chromatin: the elusive $30 \mathrm{~nm}$ fiber. Cell 2007, I 28:65 |-654.

4. Azuara V, Perry P, Sauer S, Spivakov M, Jorgensen HF, John RM, Gouti M, Casanova M, Warnes G, Merkenschlager M, Fisher AG: Chromatin signatures of pluripotent cell lines. Nat Cell Biol 2006, 8:532-538.

5. Bernstein BE, Mikkelsen TS, Xie X, Kamal M, Huebert DJ, Cuff J, Fry B, Meissner A, Wernig M, Plath K, Jaenisch R, Wagschal A, Feil R, Schreiber SL, Lander ES: A bivalent chromatin structure marks key developmental genes in embryonic stem cells. Cell 2006, I 25:315-326.

6. Mikkelsen TS, Ku M, Jaffe DB, Issac B, Lieberman E, Giannoukos G, Alvarez P, Brockman W, Kim TK, Koche RP, Lee W, Mendenhall E, O'Donovan A, Presser A, Russ C, Xie X, Meissner A, Wernig M, Jaenisch R, Nusbaum C, Lander ES, Bernstein BE: Genome-wide maps of chromatin state in pluripotent and lineage-committed cells. Nature 2007, 448:553-560.

7. Stock JK, Giadrossi S, Casanova M, Brookes E, Vidal M, Koseki H, Brockdorff N, Fisher AG, Pombo A: Ring I-mediated ubiquitination of $\mathrm{H} 2 \mathrm{~A}$ restrains poised RNA polymerase II at bivalent genes in mouse ES cells. Nat Cell Biol 2007, 9:|428-|435.

8. Noer A, Lindeman LC, Collas P: Histone $\mathbf{H 3}$ modifications associated with differentiation and long-term culture of mesenchymal adipose stem cells. Stem Cells Dev 2009, I 8:725-736.

9. Araki Y, Wang Z, Zang C, Wood WH 3rd, Schones D, Cui K, Roh TY, Lhotsky B, Wersto RP, Peng W, Becker KG, Zhao K, Weng NP: Genome-wide analysis of histone methylation reveals chromatin state-based regulation of gene transcription and function of memory CD8+ T cells. Immunity 2009, 30:912-925.

10. Cui K, Zang C, Roh TY, Schones DE, Childs RW, Peng W, Zhao K: Chromatin signatures in multipotent human hematopoietic stem cells indicate the fate of bivalent genes during differentiation. Cell Stem Cell 2009, 4:80-93.
II. Rodriguez J, Munoz M, Vives L, Frangou CG, Groudine M, Peinado MA: Bivalent domains enforce transcriptional memory of DNA methylated genes in cancer cells. Proc Natl Acad Sci USA 2008, I05:19809-19814.

12. Rasmussen EB, Lis JT: Short transcripts of the ternary complex provide insight into RNA polymerase II elongational pausing. J Mol Biol 1995, 252:522-535.

13. Law A, Hirayoshi K, O'Brien T, Lis JT: Direct cloning of DNA that interacts in vivo with a specific protein: application to RNA polymerase II and sites of pausing in Drosophila. Nucleic Acids Res 1998, 26:919-924.

14. Lis J: Promoter-associated pausing in promoter architecture and postinitiation transcriptional regulation. Cold Spring Harb Symp Quant Biol 1998, 63:347-356.

15. Krumm A, Hickey LB, Groudine M: Promoter-proximal pausing of RNA polymerase II defines a general rate-limiting step after transcription initiation. Genes Dev 1995, 9:559-572.

16. Krumm A, Meulia T, Brunvand M, Groudine M: The block to transcriptional elongation within the human c-myc gene is determined in the promoter-proximal region. Genes Dev 1992, 6:2201-2213.

17. Guenther MG, Levine SS, Boyer LA, Jaenisch R, Young RA: A chromatin landmark and transcription initiation at most promoters in human cells. Cell 2007, I30:77-88.

18. Radonjic M, Andrau JC, Lijnzaad P, Kemmeren P, Kockelkorn TT, van Leenen D, van Berkum NL, Holstege FC: Genome-wide analyses reveal RNA polymerase II located upstream of genes poised for rapid response upon $S$. cerevisiae stationary phase exit. Mol Cell 2005, I 8: 171-183.

19. Bernstein BE, Meissner A, Lander ES: The mammalian epigenome. Cell 2007, I 28:669-68I.

20. Muse GW, Gilchrist DA, Nechaev S, Shah R, Parker JS, Grissom SF, Zeitlinger J, Adelman K: RNA polymerase is poised for activation across the genome. Nat Genet 2007, 39:|507-I5I I.

2I. Zeitlinger J, Stark A, Kellis M, Hong JW, Nechaev S, Adelman K, Levine $M$, Young RA: RNA polymerase stalling at developmental control genes in the Drosophila melanogaster embryo. Nat Genet 2007, 39:1512-1516.

22. Price DH: Poised polymerases: on your mark...get set...go! Mol Cell 2008, 30:7-10.

23. Nechaev S, Adelman K: Promoter-proximal Pol II: when stalling speeds things up. Cell Cycle 2008, 7:1539-I544.

24. Barski A, Cuddapah S, Cui K, Roh TY, Schones DE, Wang Z, Wei G, Chepelev I, Zhao K: High-resolution profiling of histone methylations in the human genome. Cell 2007, 129:823-837.

25. Roh TY, Cuddapah S, Cui K, Zhao K: The genomic landscape of histone modifications in human $\mathbf{T}$ cells. Proc Natl Acad Sci USA 2006, I03: I5782-I5787.

26. Roh TY, Cuddapah S, Zhao K: Active chromatin domains are defined by acetylation islands revealed by genome-wide mapping. Genes Dev 2005, 19:542-552.

27. Schones DE, Cui K, Cuddapah S, Roh TY, Barski A, Wang Z, Wei G, Zhao K: Dynamic regulation of nucleosome positioning in the human genome. Cell 2008, I 32:887-898.

28. Wang Z, Zang C, Rosenfeld JA, Schones DE, Barski A, Cuddapah S, Cui K, Roh TY, Peng W, Zhang MQ, Zhao K: Combinatorial patterns of histone acetylations and methylations in the human genome. Nat Genet 2008, 40:897-903.

29. Chen X, Wang J, Woltring D, Gerondakis S, Shannon MF: Histone dynamics on the interleukin-2 gene in response to $\mathrm{T}$-cell activation. Mol Cell Biol 2005, 25:3209-3219.

30. Johnson WE, Li W, Meyer CA, Gottardo R, Carroll JS, Brown M, Liu XS: Model-based analysis of tiling-arrays for ChIP-chip. Proc Natl Acad Sci USA 2006, I 03: I 2457-12462.

31. Barrera LO, Li Z, Smith AD, Arden KC, Cavenee WK, Zhang MQ, Green RD, Ren B: Genome-wide mapping and analysis of active promoters in mouse embryonic stem cells and adult organs. Genome Res 2008, I 8:46-59.

32. Kress E, Hedges JF, Jutila MA: Distinct gene expression in human Vdeltal and Vdelta2 gammadelta T cells following non-TCR agonist stimulation. Mol Immunol 2006, 43:2002-20II.

33. Schubeler D, MacAlpine DM, Scalzo D, Wirbelauer C, Kooperberg C, van Leeuwen F, Gottschling DE, O'Neill LP, Turner BM, Delrow J, Bell $S P$, Groudine M: The histone modification pattern of active genes revealed through genome-wide chromatin analysis of a higher eukaryote. Genes Dev 2004, I 8: I 263- I27I.

34. Margaritis T, Holstege FC: Poised RNA polymerase II gives pause for thought. Cell 2008, I33:58I-584. 
35. Bannister AJ, Schneider R, Myers FA, Thorne AW, Crane-Robinson C, Kouzarides T: Spatial distribution of di- and tri-methyl lysine $\mathbf{3 6}$ of histone $\mathbf{H 3}$ at active genes. J Biol Chem 2005, 280: I7732-I7736.

36. Liang MD, Zhang Y, McDevit D, Marecki S, Nikolajczyk BS: The interleukin-Ibeta gene is transcribed from a poised promoter architecture in monocytes. I Biol Chem 2006, 281:9227-9237.

37. Edmunds JW, Mahadevan LC, Clayton AL: Dynamic histone $\mathbf{H 3}$ methylation during gene induction: HYPB/Setd2 mediates all H3K36 trimethylation. EMBO J 2008, 27:406-420.

38. Brettingham-Moore KH, Sprod OR, Chen X, Oakford P, Shannon MF, Holloway AF: Determinants of a transcriptionally competent environment at the GM-CSF promoter. Nucleic Acids Res 2008, 36:2639-2653.

39. Kim TH, Barrera LO, Zheng M, Qu C, Singer MA, Richmond TA, Wu $Y$, Green RD, Ren B: A high-resolution map of active promoters in the human genome. Nature 2005, 436:876-880.

40. Pokholok DK, Harbison CT, Levine S, Cole M, Hannett NM, Lee TI, Bell GW, Walker K, Rolfe PA, Herbolsheimer E, Zeitlinger J, Lewitter F, Gifford DK, Young RA: Genome-wide map of nucleosome acetylation and methylation in yeast. Cell 2005, I 22:517-527.

4I. Bernstein BE, Kamal M, Lindblad-Toh K, Bekiranov S, Bailey DK, Huebert DJ, McMahon S, Karlsson EK, Kulbokas EJ 3rd, Gingeras TR, Schreiber SL, Lander ES: Genomic maps and comparative analysis of histone modifications in human and mouse. Cell 2005, I 20:169-181.

42. Hargreaves DC, Horng T, Medzhitov R: Control of inducible gene expression by signal-dependent transcriptional elongation. Cell 2009, I 38: | 29- | 45.

43. Jiang $\mathrm{H}$, Zhang $\mathrm{F}$, Kurosu T, Peterlin BM: Runx I binds positive transcription elongation factor $b$ and represses transcriptional elongation by RNA polymerase II: possible mechanism of CD4 silencing. Mol Cell Biol 2005, 25: I0675-I0683.

44. Fujita T, Ryser S, Tortola S, Piuz I, Schlegel W: Gene-specific recruitment of positive and negative elongation factors during stimulated transcription of the MKP-I gene in neuroendocrine cells. Nucleic Acids Res 2007, 35:1007-1017.

45. Blau J, Xiao H, McCracken S, O'Hare P, Greenblatt J, Bentley D: Three functional classes of transcriptional activation domain. Mol Cell Biol 1996, 16:2044-2055.

46. Lemon B, Tjian R: Orchestrated response: a symphony of transcription factors for gene control. Genes Dev 2000, | 4:255 I-2569.

47. Ramirez-Carrozzi VR, Braas D, Bhatt DM, Cheng CS, Hong C, Doty $K R$, Black JC, Hoffmann A, Carey M, Smale ST: A unifying model for the selective regulation of inducible transcription by $\mathrm{CpG}$ islands and nucleosome remodeling. Cell 2009, I38:| |4- | 28.

48. Roh TY, Zhao K: High-resolution, genome-wide mapping of chromatin modifications by GMAT. Methods Mol Biol 2008, 387:95-108.

49. O'Brien T, Lis JT: RNA polymerase II pauses at the 5' end of the transcriptionally induced Drosophila hsp70 gene. Mol Cell Biol I99|, I I:5285-5290.

50. Rougvie AE, Lis JT: The RNA polymerase II molecule at the 5' end of the uninduced hsp70 gene of $D$. melanogaster is transcriptionally engaged. Cell I988, 54:795-804.

51. Saunders A, Core LJ, Lis JT: Breaking barriers to transcription elongation. Nat Rev Mol Cell Biol 2006, 7:557-567.

52. Murray EL, Schoenberg DR: A+U-rich instability elements differentially activate $5^{\prime}-3^{\prime}$ and $3^{\prime}-5^{\prime}$ mRNA decay. Mol Cell Biol 2007, 27:279|-2799.

53. Garber ME, Jones KA: HIV-I Tat: coping with negative elongation factors. Curr Opin Immunol 1999, I I:460-465.

54. Grondin B, Lefrancois M, Tremblay M, Saint-Denis M, Haman A, Waga K, Bedard A, Tenen DG, Hoang T: c-Jun homodimers can function as a context-specific coactivator. Mol Cell Biol 2007, 27:2919-2933.

55. Rao S, Procko E, Shannon MF: Chromatin remodeling, measured by a novel real-time polymerase chain reaction assay, across the proximal promoter region of the IL-2 gene. J Immunol 200I, I 67:4494-4503. 